\title{
1 Toward objective rockfall trajectory simulation using a stochastic impact model
}

2

3 Franck Bourrier ${ }^{a^{*}}$, Luuk Dorren $^{\mathrm{b}}$, François Nicot ${ }^{\mathrm{a}}$, Frédéric Berger ${ }^{\mathrm{a}}$ and Félix Darve $^{\mathrm{c}}$

4

a Cemagref - 2, rue de la Papeterie - BP 76 - 38402 Saint Martin d'Hères Cedex-France

b Federal Office for the Environment FOEN - Hazard Prevention Division - 3003 Bern - Switzerland c L3S-R - INPG, UJF, CNRS - Domaine Universitaire - BP 53 - 38041 Grenoble Cedex 9 - France *Corresponding author. Tel.: $+33 \quad 4 \quad 76 \quad 76 \quad 27$ 27; Fax: $+33 \quad 4 \quad 76 \quad 51 \quad 38$ 03; E-mail: franck.bourrier@cemagref.fr.

\section{Abstract:}

The accuracy of rockfall trajectory simulations depends to a large extent on the calculation of the rebound of falling boulders on different parts of a slope where rockfalls could occur. The models commonly used for rebound calculation are based on restitution coefficients, which can only be calibrated subjectively in the field. To come up with a robust and objective procedure for rebound calculation, a stochastic impact model associated with an objective field data collection method was developed and tested in this study. The aims of this work were to assess the adequacy of this approach and to evaluate the minimum amount of field data required to obtain simulation results with a satisfactory level of predictability. To achieve these objectives, the rebound calculation procedure developed was integrated into a three-dimensional rockfall simulation model, and the simulated results were compared with those obtained from field rockfall experiments. For rocky slopes, the simulations satisfactorily predict the experimental results. This approach is advantageous because it combines precise modelling of the mechanisms involved in the rebound and of their related variability with an objective field data collection procedure which basically only requires collecting the mean size of soil rocks. The approach proposed in this study therefore constitutes an excellent basis for the objective probabilistic assessment of rockfall hazard. 
27 Keywords: 3D simulations; field experiments; restitution coefficients; rockfall rebound; stochastic modelling; Rockyfor3D.

\section{Introduction}

As shown by the recent accidents occurring in March 2006 in the French Alps and June 2006 on the Gotthard highway in Switzerland, rockfall is one of the main natural hazards that pose risks to residential areas, infrastructures, and populations in the Alps. Rockfall is generally defined as the removal of individual boulders from a cliff face (Varnes, 1978; Whalley, 1984; Selby, 1993; Cruden and Varnes, 1996). This study focuses on single falling rocks with a volume up to $1.3 \mathrm{~m}^{3}$. In rockfall hazard assessment, trajectory simulation models are increasingly used for designing protective measures such as nets and dams (Descoeudres, 1997; Peila et al., 1998; Nicot et al., 2001, 2007) or for making hazard maps (Kobayashi et al., 1990; Evans and Hungr, 1993; Guzzetti et al., 2002; Chau et al., 2004; Jaboyedoff et al., 2005; Bourrier et al., 2008b; Frattini et al., 2008).

The most difficult process to simulate in such trajectory models is the rebound, which describes the impact of the falling boulder on the slope surface. To calculate such a rebound, a wide range of algorithms is currently available, which are summarised in Guzzetti et al. (2002), Dorren (2003), and Heidenreich (2004). Rebound deterministic modelling remains highly speculative since the information available on the mechanical and geometrical properties of the soil is not sufficient to perform a relevant deterministic prediction of boulder rebound. In particular, the characterisation of the spatial distributions of the parameters required for rebound calculation generally result from a field survey which, for practical reasons, cannot be exhaustive. Stochastic approaches have therefore been proposed (Paronuzzi, 1989; Pfeiffer and Bowen, 1989; Azzoni et al., 1995; Dudt and Heidenreich, 2001; Guzzetti et al., 2002; Agliardi and Crosta, 2003; Jaboyedoff et al., 2005; Bourrier et al., 2007, 2008b; Frattini et al., 2008) to account for the variability of the rebound. Most of these approaches are based on two parameters, both 
1985; Bozzolo and Pamini, 1986; Chau et al., 1998; Ushiro et al., 2000; Chau et al., 2002; Heidenreich, 2004). The problem is that stochastic variation of the restitution coefficients only account for the variability related to terrain characteristics. Variability due to the kinematics of the falling boulder is not accounted for. In addition, estimating the values of these two parameters in the field is a difficult task mainly based on literature values that are associated with certain surface characteristics of the slope. Overviews of commonly used values for restitution coefficients are given in (Paronuzzi, 1989; Pfeiffer and Bowen, 1989; Azzoni et al., 1992; Azzoni and De Freitas, 1995; Chau et al., 2002; Agliardi and Crosta, 2003; Scioldo, 2006). Most models are very sensitive to the values of these restitution coefficients. In addition, the values in the literature vary significantly for identical surface characteristics. The resulting subjectivity in the choice of these parameter values therefore partly explains the large variation in the results obtained when applying different models, or even the same model used by different operators, at the same site (Interreg IIc, 2001; Berger and Dorren, 2006).

To overcome these difficulties, a more objective rebound calculation procedure based on a stochastic impact model was developed. This procedure models the variability associated with the rebound and only requires collecting a very limited set of field parameters: the size of the falling boulder and the sizes characterising the rocks composing the slope surface. Our first objective was to test and validate the procedure developed. The second objective was to evaluate the minimum amount of field data required to obtain simulation results with a satisfactory level of predictability.

This paper first explains the rebound calculation procedure developed and its integration into a threedimensional rockfall trajectory simulation model. Then the simulation results are compared with those obtained from field rockfall experiments and discussed.

\section{Full-scale rockfall experiments on a mountain slope}

Full-scale rockfall experiments were carried out in an avalanche track in the Forêt Communale de Vaujany in France (N. $45^{\circ} 12^{\prime}$, E. $6^{\circ} 3^{\prime}$ ). The study area covers an Alpine slope ranging from 1200 to 1400 $\mathrm{m}$ above sea level with a mean gradient of $38^{\circ}$. The experimental site is part of a hillslope that is formed 
by a postglacial talus slope (Fig. 1), downslope from rock faces consisting of the "Granite des Sept Laux", which belong to the crystalline Belledonne massif. The talus cone mainly consists of rock avalanche, snow avalanche, and rockfall deposits. The study site is $\sim 100 \mathrm{~m}$ wide and $570 \mathrm{~m}$ long (distance between the starting point and the lower forest road, measured along the slope). Between the starting point and the lower forest road, it has the shape of a channel with a maximum depth and width of 2 and $10 \mathrm{~m}$, respectively. Since avalanches occur every year in this channel, it is denuded of trees.

Fig. 1.

The protocol was identical for all rockfall experiments. Before each boulder release, the volume of the boulder was measured and the boulder was coloured with biodegradable paint so that it left traces after rebounding on the slope. The volume was estimated by measuring the height, width, and depth along the three most dominant boulder axes and by assuming that the boulders were rectangular. A total of 100 boulders were released individually, one after the other. The mean volume was $0.8 \mathrm{~m}^{3}$, and the standard deviation $0.15 \mathrm{~m}^{3}$ (Fig. 2).

Fig. 2.

93

A front shovel was used to release the boulders down the slope, starting with a free fall of $5 \mathrm{~m}$. As soon as the boulder stopped, the impact locations and stopping points were captured with an Impulse LR 200 laser distance meter manufactured by Laser Technology, Inc. (Centennial, CO, USA). In addition, the rockfall trajectories were filmed by five digital cameras, which were placed so that the camera planes were perpendicular to the channel, which is the preferred rockfall path, and $30 \mathrm{~m}$ away (Fig. 1). The cameras were fixed at a height of $10 \mathrm{~m}$ in trees. Additional details on the experiments are given in Dorren et al. (2006). 
101 The digital films of the 100 rockfall trajectories were analysed using image processing software called

102 AviStep 2.1.1 (developed by M. Delabaere, St. Denis de la Réunion, France). This program extracts the 103 position and the velocity of a moving particle for each individual image in a digital film using the 104 following principle. First, in the first image of each film, the field-measured rebound distances are 105 identified. Second, soil surface detection is conducted by linking the successive impact points in the films 106 assuming that soil surface is linear between two impact points. Third, the two-dimensional trajectory of 107 each falling boulder was analysed using a sequence of movie images (Fig. 3). Finally, the analysis of the 108 movie images provided the rebound heights, i.e., the maximum vertical distance between the centre of the 109 boulder and the slope's surface, as well as the position of the boulder for every image (every $0.04 \mathrm{~s}$ ). This 110 makes it possible to determine the velocity.

111 Since the resolution of the movie images did not allow for a precise measurement of the rotational 112 velocity, only the translational kinetic energy $E_{\text {trans }}$ was calculated to reduce the uncertainty in the results.

113 The translational kinetic energy $E_{\text {trans }}$ of a falling boulder is calculated as:

$114 \quad E_{\text {trans }}=\frac{1}{2} m_{b} V^{2}$

115 where $m_{\mathrm{b}}$ is the mass, and $V$ is the translational velocity of the boulder.

116 The experimental results therefore do not provide information on either the rotational kinetic energy $E_{\text {rot }}$ 117 or the total kinetic energy $E_{\text {tot }}$, which are defined as follows:

$118 \quad E_{r o t}=\frac{1}{2} I_{b} \omega^{2}$

119 and

$120 E_{\text {tot }}=E_{\text {trans }}+E_{\text {rot }}$

121 where $I_{\mathrm{b}}$ is the moment of inertia, and $\omega$ is the rotational velocity of the boulder.

123 Fig. 3.

124 


\section{Trajectory simulation using a stochastic rebound algorithm}

126 The simulation model used is the 3D rockfall trajectory model Rockyfor3D, which has been developed 127 since 1998 (Dorren et al., 2006). This model simulates the rockfall trajectory in 3D by calculating 128 sequences of parabolic free fall through the air and rebounds on the slope, as well as impacts against 129 trees, if specified. Rolling is represented by a sequence of short-distance rebounds and sliding is not 130 modelled. Falling boulders are represented in the model by spheres using a hybrid approach. This means 131 that, during parabolic free fall, the falling sphere is represented by a single point (lumped mass) and, 132 during the rebound calculation, by a real sphere. The three major components of Rockyfor3D are 1) the 133 parabolic free fall calculation and its intersection with the topography, 2) the rebound calculation, and 3) 134 the fall direction calculation after rebound.

\subsection{Parabolic free fall}

136 The parabolic free fall is calculated with a standard algorithm for a uniformly accelerated parabolic

137 movement through the air. This calculation determines the position and the normal (with respect to the 138 local slope) $V_{\mathrm{n}}^{\text {in }}$, tangential $V_{\mathrm{t}}^{\text {in }}$, and rotational $\omega^{\text {in }}$ velocities at the intersection with the slope topography, 139 represented by a Digital Elevation Model (DEM). As such, Rockyfor3D simulates a 3D trajectory by 140 calculating the displacement of the boulder position along the $x$-, $y$-, and $z$-axes (Fig. 4). Here, the $z$-axis 141 corresponds to its vertical position, the $x$-axis to the east-west direction, and the $y$-axis to the north-south 142 direction (Fig. 4A). By its $x$ and $y$ coordinates, the 3D trajectory is linked to a set of raster maps with a 143 resolution between 1 and roughly $20 \mathrm{~m}$. For this study, however, the raster resolution was $2.5 \mathrm{~m}$. The 144 raster maps provide information on the topography (DEM), the slope surface characteristics, and the 145 release points (for this study, only one release raster cell was defined).

146 Knowing the position of the rebound and the slope surface characteristics defined by the raster maps at 147 this position, as well as the velocities before rebound, the rebound calculation using the stochastic impact 148 model can be initiated. 


\subsection{Stochastic impact model}

153 The rebound calculation determines the normal $V_{\mathrm{n}}^{\text {out }}$, tangential $V_{\mathrm{t}}^{\text {out }}$, and rotational $\omega^{\text {out }}$ velocities after 154 rebound based on the velocities before rebound, called incident velocities, and on the parameters 155 determining the energy loss during the rebound. The rebound model initially integrated in Rockyfor3D 156 (Dorren et al., 2006) was replaced by a stochastic impact model that calculates the velocity vector after 157 rebound $\boldsymbol{V}^{\text {out }}$ from the velocity vector before rebound $\boldsymbol{V}^{\text {in }}$ following the expression:

$158 \quad \mathbf{V}^{\text {out }}=\mathbf{A} \mathbf{V}^{\text {in }}$ with $\mathbf{V}^{\text {out }}=\left[\begin{array}{c}V_{t}^{\text {out }} \\ V_{n}^{\text {out }} \\ \omega^{\text {out }}\end{array}\right], \mathbf{A}=\left[\begin{array}{ccc}a_{1} & a_{2} & a_{3} \\ a_{4} & a_{5} & a_{6} \\ a_{7} & a_{8} & a_{9}\end{array}\right], \mathbf{V}^{\text {in }}=\left[\begin{array}{c}V_{t}^{\text {in }} \\ V_{n}^{\text {in }} \\ \omega^{\text {in }}\end{array}\right]$

159 This means that each of the three velocities after rebound $\left(V_{\mathrm{t}}^{\text {out }}, V_{\mathrm{n}}^{\text {out }}\right.$, and $\left.\omega^{\text {out }}\right)$ is calculated with the three 160 incident velocity components $\left(V_{\mathrm{t}}^{\text {in }}, V_{\mathrm{n}}^{\text {in }}\right.$, and $\left.\omega^{\text {in }}\right)$ and three coefficients of matrix $\mathbf{A}$.

161 For example, the tangential component of the velocity after rebound $V_{t}^{\text {out }}$ is expressed as follows:

163 The coefficients $a_{\mathrm{i}}$, as well as the correlations between them, are characterised by normal probability

164 distribution functions. These allow the model to account for the high variability of the local slope surface 165 characteristics and the kinematics of the rebounding sphere. Specific information can be found in Bourrier 166 et al. $(2007,2008 b)$.

Fig. 5.

169

170 Because of the defined inter-relationships between the outgoing and incident velocity components, the 171 stochastic impact model differs completely from classical rebound algorithms. Most of these only use a 172 tangential $R_{\mathrm{t}}$ and a normal $R_{\mathrm{n}}$ restitution coefficient for different slope surface types (see Guzzetti et al., 
173 2002; Dorren, 2003), which are defined by the user but are not related to all three incident velocity 174 components. Many authors have already revealed that this approach introduces errors in rebound 175 calculations. The $R_{\mathrm{t}}$ and $R_{\mathrm{n}}$ coefficients are defined as follows:

$176 \quad R_{t}=\frac{V_{t}^{\text {out }}}{V_{t}^{\text {in }}}$

$177 \quad R_{n}=-\frac{V_{n}^{\text {out }}}{V_{n}^{\text {in }}}$

178 Contrary to classical models, the restitution coefficients $R_{\mathrm{t}}$ and $R_{\mathrm{n}}$ that can be recalculated from the 179 velocities before and after rebound as predicted by the stochastic impact model are not constant values. 180 They both depend on all the incident kinematic parameters and the terrain characteristics. Figure 6 shows 181 an example of the effect of the incident angle on the mean restitution coefficients $R_{\mathrm{t}}$ and $R_{\mathrm{n}}$ predicted by 182 the stochastic impact model.

184 Fig. 6.

186 The values of the coefficients $a_{\mathrm{i}}$ defined in matrix $\mathbf{A}$ are derived from the statistical analyses of a large 187 data set obtained from numerical simulations of impacts (Bourrier et al., 2007, 2008a, 2008b). These 188 numerical simulations of impacts were previously calibrated from laboratory experiments of the impact of 189 a 10-cm spherical rock on a coarse soil composed of gravels ranging from $1 \mathrm{~cm}$ to $5 \mathrm{~cm}$ (Bourrier et al.,

190 2008b). The adequate agreement between the laboratory experiments and the numerical simulations of 191 impacts proves that the impact simulations, and consequently the stochastic impact model, satisfactorily 192 express the energy transfers occurring during the impact of a boulder on a coarse soil. Although the 193 calibration of the numerical model of impacts was satisfactory, one limitation could stem from the 194 differences in the size of the impacting and soil rocks during calibration and during application in this 195 study. However, the influence of the scale change effects was proved to be small by comparing the results 196 of the numerical simulations of impacts at different scales (Bourrier, 2008). 
197 For this study, the parameters of the stochastic impact model were determined for five fixed ratios, which

198 have the values $1,2,3,4$, and 5, between the radius of the falling boulder $R_{\mathrm{b}}$ and the mean radius of the 199 particles constituting the slope surface $R_{\mathrm{m}}$. For each $R_{\mathrm{b}} / R_{\mathrm{m}}$ ratio, a fixed set of model parameters was 200 calculated. For larger ratios, the model has not yet been calibrated, which means that it is currently not 201 suitable for rebounds of large boulders on fine soils.

\subsection{Calculation of the fall direction}

203 The fall direction in the $x-y$ plane is primarily determined by the slope topography at the rebound position 204 and is calculated by a probabilistic algorithm. During each subsequent rebound, the model allows the 205 sphere to deviate from its direction before rebound towards the direction of the aspect of the raster cell in 206 which the boulder rebounds (Figs. 5 and 7). The aspect is the downslope direction of the maximum rate of 207 change in value from each cell in a raster to its neighbouring ones and represents the steepest slope 208 direction. The deviation angle $\delta$ (Fig. 5) is determined by a random number that defines whether the 209 boulder is deviated between 0 and $22.5^{\circ}$ from its original direction, or $22.5-45^{\circ}$, or $45-50^{\circ}$. The first case 210 has a $72 \%$ probability of occurrence, the second one has a $24 \%$ probability, and the third one a $4 \%$ 211 probability (Fig. 7). These deviation angles and their related probabilities are based on the experimental 212 results presented in Dorren et al. (2005). If the sphere moves upslope, a maximum deviation of $22.5^{\circ}$ is 213 allowed for both directions lateral to the direction before rebound. If the boulder enters a depression in the 214 DEM, the direction before and after rebound remains unchanged.

216 Fig. 7.

\subsection{Input data}

219 The DEM used for the experimental site covers an area from the release point to the opposite river bank in the valley bottom. The DEM was created using inverse distance-weighted interpolation (see for 
221 instance Weber and Englund, 1992) of, on average, three $x, y, z$ points per DEM cell. These points were 222 collected in the field with a detailed topographical survey using a laser distance meter and a compass. The 223 topographical survey was conducted so that a mean density of 1 point $/ \mathrm{m}$ was available in all directions. 224 We created this DEM because, due to the surrounding forest cover, GPS measurements are not accurate 225 on the study site and a high-resolution, photogrammetric or LiDAR-derived DEM was not available. 226 Verification with an available 10-m DEM and an orthophoto showed that the accuracy of the created 227 DEM was about $1 \mathrm{~m}$ in the $x-y$ plane and $0.5-1.5 \mathrm{~m}$ in the $z$-direction.

228 At the release point, boulders were dropped from a height of $5 \mathrm{~m}$. The simulated boulders were assumed 229 to be spherical, and the distribution of their volumes was identical to the experimental distribution (Fig. 230 2). The errors associated with volume estimation were therefore the same in the experiments and in the 231 simulations. Volume estimation errors were reduced as much as possible by choosing the released 232 boulders in a quarry so that they were as spherical as possible.

233 The slope surface characteristics were determined in the field by identifying homogenous zones that are 234 represented as polygons on a map (Fig. 1). Each polygon defines the size of the material covering the 235 slope. To represent the size of the surface material in this polygon map, we used two different 236 approaches. The first one, which is called method A ("size classes"), describes the surface with three size 237 probability classes according to Dorren et al. (2006). The second one, called method B ("mean size"), is a 238 more simplified description, which is based only on the mean radius $R_{\mathrm{m}}$ of the material covering the 239 slope. Method A aims at giving a precise description of the size of the surface material and its variation. 240 The method uses three roughness classes $R g_{70}, R g_{20}$, and $R g_{10}$. These classes represent the diameter of the 241 obstacle, corresponding to rocks covering the soil surface, encountered by a falling boulder during $70 \%$, $24220 \%$, and $10 \%$, respectively, of the rebounds in a homogenous zone. For method A, the field survey 243 therefore consists of estimating the equivalent diameter of the rocks covering the soil surface 244 corresponding to the three classes $R g_{70}, R g_{20}$, and $R g_{10}$ in each homogenous zone on the study slope. 245 During each rebound calculation, the mean radius $R_{\mathrm{m}}$ of the material encountered by the impacting 246 boulder was randomly chosen from the three material size values $R g_{70}, R g_{20}$, and $R g_{10}$ given their 
accompanying probabilities. In method $\mathrm{B}$, only one mean radius $R_{\mathrm{m}}$ value represented the material size in each homogenous zone. Rebound was therefore calculated by considering $R_{\mathrm{m}}$ the mean radius of the rock encountered by the falling boulder in a given zone.

250 In the rebound model used, the value of the $R_{\mathrm{b}} / R_{\mathrm{m}}$ ratio is rounded to the nearest integer with a maximum 251 of 5. A set of rebound model parameters ( $a_{\mathrm{i}}$ coefficients $)$ was determined depending on the value of the $R_{\mathrm{b}} / R_{\mathrm{m}}$ ratio. Table 1 reports the values used for all the polygons defined and shown on the map in Fig. 1.

Table 1.

\subsection{Simulation scenarios}

Rockfall trajectory simulations were carried out using method A ("size classes") and method B ("mean size"). For each method, 100, 1000, 2000, 5000, and 10000 falling boulders were simulated. For each set of simulations, the probability distribution functions of the velocity, translational kinetic energy, and passing height were compared with the corresponding experimental distributions at two "evaluation lines"

(Figure 1). Evaluation line 1 (EL1) was located $185 \mathrm{~m}$ from the starting point, measured along the slope,

262 directly in the centre of the viewing plane of camera 4. Evaluation line 2 (EL2) was located after $235 \mathrm{~m}$, in the centre of the viewing plane of camera 5. In addition, the spatial patterns of the trajectories, the 264 passing frequencies per raster cell, and the stopping locations of the simulated boulders were analysed.

265 The latter were compared with stopping locations observed during the field rockfall experiments.

\subsection{Rebound analysis}

267 If the agreement between the experimental and simulated results is satisfactory, the simulations can 268 collect additional information on the kinematics of the falling boulders, which cannot be measured during 269 the full-scale field experiments. First, precise values of the rotational kinetic energy of the falling boulders at EL1 and EL2 can be obtained from simulations, whereas the rotation of the falling boulder 
271 cannot be precisely measured from the experimental films. In the simulations, the rotational kinetic 272 energy of the falling boulder $E_{\mathrm{rot}}$ can therefore be compared with the translational kinetic energy of the 273 falling boulder $E_{\text {trans }}$ and with the total kinetic energy of the falling boulder $E_{\text {tot. }}$.

274 Information regarding the incident kinetic energy for all rebounds can also be collected, whereas this is 275 not possible from field experiments. In particular, for each rebound, the simulations provide information 276 on the distribution of the incident kinetic energy between the tangential, normal, and rotational incident 277 velocity components. Starting from Eqs. 1, 2, and 3, the incident kinetic energy $E_{\text {tot }}^{\text {in }}$ is divided into 278 normal incident energy $E_{\mathrm{n}}^{\mathrm{in}}$, tangential incident energy $E_{\mathrm{t}}^{\mathrm{in}}$, and rotational incident energy $E_{\mathrm{rot}}^{\mathrm{in}}$ defined 279 as follows:

$280 \quad E_{t o t}^{i n}=E_{t}^{i n}+E_{n}^{i n}+E_{r o t}^{i n}$

$281 \quad E_{t}^{i n}=\frac{1}{2} m_{b}\left(V_{t}^{i n}\right)^{2}$

$282 \quad E_{n}^{i n}=\frac{1}{2} m_{b}\left(V_{n}^{i n}\right)^{2}$

$283 \quad E_{\text {rot }}^{i n}=\frac{1}{2} I_{b}\left(\omega^{i n}\right)^{2}$

284 Finally, to compare the implemented rebound algorithm to classical rebound models based on the use of 285 restitution coefficients, the $R_{\mathrm{t}}$ and $R_{\mathrm{n}}$ values obtained during the simulations were computed using the 286 classical definition given in Eqs. 6 and 7.

\section{4. Results}

2881000 rockfall simulations were required to provide stable predictions, meaning that the variation in the 289 means and standard deviations of the parameters measured on EL1 and EL2 became < 5\%. However, to 290 decrease the variation in the results as much as possible, 10000 simulations were executed for both 291 methods. 


\subsection{Kinematic results at the evaluation lines}

293 The comparisons between the experimental and simulated results at EL1 and EL2 show that both the 294 mean values and standard deviations were predicted accurately for boulder velocity, passing heights, and 295 translational kinetic energy (Table 2). However, in most cases, the simulated mean values and standard 296 deviations were slightly smaller than the experimental values. In addition, the predictions obtained using 297 method B (“mean size") were systematically closer to the experimental results than those obtained using 298 method A ("size classes"). All relative errors (RE) (Table 3) are < $21 \%$ for method B, whereas they reach 299 up to $32 \%$ for method A.

300 The shapes of the distributions of the simulated quantities were very similar for methods A and B (Fig. 8).

301 These distributions were also similar to those obtained from the experimental results. On the contrary, the 302 maximum values were overestimated by the simulations, irrespective of the method used (Table 3).

303 The statistical Kolmogorov-Smirnov test was performed to compare all the simulated distributions with 304 the corresponding experimental distributions. If the result of the test is 0 , it can be assumed that the 305 simulated and experimental results are similar. If the result is 1 , this is not the case. The similarity 306 hypothesis is rejected if the p-value associated with the test is less than 0.05 . The larger the p-value is, the 307 more plausible the hypothesis that the two samples belong to the same distribution. The results of the 308 Kolmogorov-Smirnov tests showed that method B ("mean size") provided a better prediction of the 309 experimental distributions because the similarity hypothesis was only rejected once out of 6 comparisons.

310 For method A ("size classes"), it was rejected 4 times out of 6 comparisons. In addition, the p-value 311 obtained when comparing the simulated distributions to the measured distributions were all between 0.01 312 and 0.3 whatever method was used, which means that the simulated distributions were not significantly 313 different from the experimental distributions. Both methods A and B can therefore be considered suitable 314 to simulate the experimental results.

Table 2. 
Table 3.

Table 4.

Fig. 8.

\subsection{Rockfall trajectories}

325 The numbers of boulders deposited with decreasing altitude are presented in Fig. 9, for both the 326 experimental and simulated results. The simulations, using methods A and B, provided values similar to 327 the experimental values for the distribution of stopping points, especially for boulders reaching low 328 altitudes. Interestingly, predictions using method A ("size classes") resulted in a slight underestimation of 329 the percentage of passing boulders with decreasing altitude. On the contrary, the simulations using 330 method B ("mean size") provided a slight overestimation. For boulders stopping just after the release 331 point and for boulders reaching long distances from the release point (> $350 \mathrm{~m})$, both methods predicted 332 larger percentages of passing boulders than the experimental results.

Fig. 9.

336 The comparison between simulated run-out zones and experimental stopping points (Fig. 10) showed 337 that, first, the simulated run-out zone was larger than the one observed during the experiments. Second, 338 discrepancies were observed for stopping points located below the forest road. In the experiments, two 339 distinct deposit areas were observed, whereas the simulated passing frequencies only highlighted one of 340 them located on the bottom left of the maps in Fig. 10.

Fig. 10. 
344 4.3. Information gathered from simulations

345 Since we consider that the agreement between the experimental and simulated results is highly 346 acceptable, we used the simulations to study kinematical parameters that could not be measured in the 347 field, in particular the distribution of the rotational velocity of the falling boulder (Fig. 11). The mean 348 value of the $E_{\mathrm{rot}} / E_{\mathrm{tot}}$ ratio was $6 \%$ for EL1 and $8 \%$ for EL2. In addition, the associated standard deviation 349 was $7 \%$ for EL1 and 8\% for EL2.

350

351 Fig. 11.

353 Further, the simulated $E_{\mathrm{t}}^{\mathrm{in}} / E_{\mathrm{tot}}^{\mathrm{in}}$ ratios (Fig. 12) showed that most of the incident energy was associated 354 with the tangent-to-soil-surface component of the incident velocity. This result was confirmed by the 355 distribution of the incidence angle (Fig. 13), which highlights the small values of this angle. Finally, the 356 simulation results provided information on the distribution of $R_{\mathrm{t}}$ and $R_{\mathrm{n}}$ restitution coefficients for all 357 rebounds, as shown in Fig. 14.

359 Fig. 12.

361 Fig. 13.

363 Fig. 14. 


\section{Discussion}

\subsection{Comparison of the experimental and simulation results}

367 The comparisons of the experimental and simulated results, using methods $\mathrm{A}$ and $\mathrm{B}$, showed that the 3D 368 trajectory simulation could predict rockfall trajectories and kinematics. Reproducible simulation results 369 were obtained from 1000 simulations onwards, which makes 3D trajectory simulation feasible. However, 370 in this study, there were fewer sources of variability than in the daily practice of rockfall hazard assessment. In particular, the rockfall starting position and the boulder volumes were exactly known. In practice, the latter are not always easy to predict.

373 The differences between the observed and simulated distributions, the maximum values in particular,

374 could stem from the fact that, in the experiments, the distributions were based on only 100 rockfall 375 experiments. They therefore do not represent the full asymptotic distribution that would have been 376 obtained from a very large number of experiments. However, the global shape of the distribution, such as 377 the most probable value and the global distribution of the values, was satisfactorily represented. Thus, if 378 only the global characteristics of the distributions are compared, the simulated distributions can be 379 considered good predictions, which was confirmed by the results of the Kolmogorov-Smirnov test, in 380 particular for method B ("mean size").

381 The comparisons between the simulated and the experimental stopping points showed the capability of 382 the rockfall model to predict run-out distances (Fig. 9). However, Fig. 9 shows that method B ("mean 383 size") approached the experimentally observed deposit pattern best. Neither method A nor B reproduced 384 the number of boulders stopping in the upslope section of the test site. These blocks stopped within the 385 first $20-40 \mathrm{~m}$ from the release point due to sliding on the side with the largest surface after the first 386 rebound. Figure 9 shows that this accounted for $\sim 5 \%$ of the released boulders. For large distances from 387 the release point ( $350 \mathrm{~m}$ and farther), the differences between the simulated and the experimental 388 maximum run-out distances (Fig. 9) resulted from the rebound algorithm not being adapted to the surface 389 material consisting of soils composed of fine particles, which was found in the valley bottom (Fig. 10). 
The algorithm was specifically developed for rocky surfaces and therefore will not produce realistic

391 results for other soil types.

392 Although the simulated run-out zones were larger than the experimental run-out zones (Fig. 10), the $1 \%$ 393 pass frequency limit, i.e., the limit passed by $1 \%$ of the boulders, correspond quite well to the 394 experimentally observed stopping points only (Fig. 10), especially for method B.

395 The existence of two deposit areas was not reproduced by the simulations. The simulated passing 396 frequency maps show two main trajectory paths upslope of the forest road, which converge into a single 397 path in the downslope section. The experimental trajectories, however, also show two distinct paths in the 398 downslope section. The difference between these experimental and simulated patterns resulted from an 399 imperfect digital representation of the terrain in the DEM south-west of the middle forest road (Fig. 15). 400 This local discrepancy induced slight changes in the pattern of the trajectory path and in the shape of the 401 run-out zone associated with the 1/100 pass frequency (Fig. 10).

Finally, the comparison of the results obtained by method A and method B raises questions on how 406 precise the parameter values estimated in the field must be. For methods A and B, the simulated 407 distributions of velocities, rebound heights, and energies (Fig. 8) as well as the run-out zones (Fig. 9) 408 were very similar. The detail of the description of the slope surface characteristics therefore only slightly 409 influences the simulation results. Our experience shows, however, that in the field it is easier to estimate 410 three size classes than a single one, as shown in Fig. 16. For example, on a slope covered with rather fine 411 scree $(<5 \mathrm{~cm})$, quite some rocks measured $10 \mathrm{~cm}$ in diameter, and $10 \%$ of the surface covered with 20 $412 \mathrm{~cm}$ rocks, it is quite difficult to estimate a single, valid, mean particle size. The "size classes" method 413 describes the mean size of the particles that cover $70 \%, 20 \%$, and $10 \%$ of the surface, with $70 \%=5 \mathrm{~cm}$, $41420 \%=10 \mathrm{~cm}$, and $10 \%=20 \mathrm{~cm}$. Since method B ("mean size") provided more accurate results, this 
implies that method A ("size classes") could be used in the field for a better estimate of the single mean particle size, so that method B ("mean size") could be used in the simulation.

Fig. 16.

\subsection{Advantages and limitations of the approach}

421 An advantage of the approach presented here is that simulation can be used to gather information that 422 cannot be obtained in the field (see section 3.6). First, the simulated distributions of the rotational kinetic energies compared to the total kinetic energy at EL1 and EL2 show that the translational velocity of the boulder mainly determines the total boulder kinetic energy (Fig. 11). One could note a slight trend toward a downhill increase in the $E_{\text {rot }} / E_{\text {tot }}$ ratio, which may be due to the specific topography of the study site. Although the rotational energy was smaller than the translational energy, the knowledge of the distribution between these two energies is essential for designing effective protective structures. The translational kinetic energy mainly determines the design of the structure (structural strength performance), whereas the rotational kinetic energy determines the capability of the structure to prevent boulders from rolling over the structure (structure shape efficiency).

Another advantage of the approach presented is the insight obtained in the commonly used coefficients $R_{\mathrm{t}}$ and $R_{\mathrm{n}}$. The values of the $R_{\mathrm{t}}$ calculated from the simulated rebounds (Fig. 14) are in accordance with

433 common values for talus slopes, but they show that the variability of $R_{\mathrm{t}}$ is even greater than assumed in 434 the literature. In contrast, the values of the $R_{\mathrm{n}}$ coefficients (Fig. 14) are extremely high compared to the 435 common values, which generally range from 0.25 to 0.65 . The dependence of $R_{\mathrm{t}}$ and $R_{\mathrm{n}}$ recalculated from 436 the stochastic impact model on the incidence angle explains this phenomenon (Fig. 6). For small 437 incidence angles, which correspond to most of the rockfall impacts in the simulations (Fig. 13), the values 438 of $R_{\mathrm{t}}$ depend only slightly on the incidence angle; they correspond to common values $\left(R_{\mathrm{t}} \approx 0.7\right.$; Fig. 14).

439 On the contrary, the values of $R_{\mathrm{n}}$ are very high $\left(R_{\mathrm{n}}>1\right)$ compared to common values (Fig. 14). However, 
in the case of a vertical impact, the $R_{\mathrm{n}}$ values predicted by the stochastic impact model (Fig. 6) are in 441 accordance with common experimental results $\left(R_{\mathrm{n}} \approx 0.4\right)$. The main reason for these differences is that the common values of $R_{\mathrm{n}}$ are generally obtained from experimental campaigns conducted for boulders falling vertically on a slope surface. This does not correspond to the simulated impact cases because simulation 444 incidence angles were, for the most part, $<50^{\circ}$, as shown in Fig. 13. The high values of $R_{\mathrm{n}}$ in the 445 simulations explain that, although the incident normal velocity $V_{\mathrm{n}}^{\text {in }}$ was small for impacts that were 446 parallel to the slope's surface, the normal velocity of the boulder after a rebound can be very high because 447 of the energy transfer from the rotational to the translational kinetic energy. This phenomenon is not 448 accounted for in classical rebound algorithms, whereas it is included in the stochastic impact model.

449 The values of $R_{\mathrm{n}}$ should therefore be chosen with caution when performing a rockfall trajectory analysis 450 using classical rebound algorithms. However, the importance of $R_{\mathrm{n}}$ is generally subordinate to $R_{\mathrm{t}}$. Indeed, 451 properly modelling the transfer of the tangential incident energy between the falling boulder and the soil 452 during a rebound is essential because Fig. 12 shows that the tangential incident energy is, in most cases, 453 determinant for the total incident energy (93\% of the calculated $E_{\mathrm{t}}^{\mathrm{in}} / E_{\text {tot }}^{\mathrm{in}}$ ratios are $\left.>0.75\right)$.

454 The two main points of interest in the rebound calculation procedure developed herein are, first, precisely 455 modelling the mechanisms governing the rebound as well as their associated variability and, second, the 456 more objective field data collection procedure. Both points are of great interest for rockfall hazard 457 mapping, which demand a satisfactory prediction of the variability of both the stopping points and the 458 kinematics of the falling boulders. Following the proposed approach, hazard mapping can be greatly 459 improved because it allows the reliable spatial characterisation of the passing frequencies as well as of the 460 mean and standard deviation values of the rockfall energies (intensity). Rockfall hazard mapping 461 approaches based on combinations of intensity and probability, such as those developed in Switzerland 462 (Raetzo et al., 2002; Jaboyedoff et al., 2005), can therefore be used with increased confidence.

463 However, this work is limited by the partial character of the validation. From a theoretical point of view, 464 the amount of experimental data is not (and almost never is) sufficient to validate simulated rare events. 
Since the performance and analysis of 1000 full-scale rockfall experiments would take roughly 10 years, one must rely on simulations to predict extreme events, even though they are not fully validated. Another limitation of this study is that the stochastic impact model developed can only be used on rocky slopes. However, similar approaches could be developed to characterise the rebound of a boulder on all types of soil provided that large data sets composed of reproducible and precisely defined impact tests are available for statistical analysis. To create these data sets, the direct use of laboratory or field experiments

471 is not suitable. However, they can be generated from numerical simulations that have previously been 472 calibrated using these experiments. That is exactly were the challenge lies.

\section{Conclusions}

474 This paper has investigated a newly developed stochastic impact model, which was implemented in an existing 3D rockfall trajectory model to calculate velocities of simulated boulders after a rebound on the slope. The first objective of this study was to assess the adequacy of the approach proposed. For this 477 purpose, a full-scale experimental program made it possible to assess the predictive capacity of this tool. 478 Comparisons between experimental and simulated results show very acceptable agreements. The second 479 objective of the study was to evaluate the minimum amount of field data required to obtain accurate 480 simulation results. The main advantages of the developed approach are the small number of parameters to 481 be assessed in the field and the clear physical meaning of these parameters. Basically, only the mean size 482 of the rocks covering the surface of the slope is required. This can be measured objectively in the field. 483 The method developed does not work for boulders impacting fine soils. We believe, however, that a 484 similar objective stochastic rebound model could be developed, based on a similar combination of 485 numerical and laboratory experiments.

486 The stochastic feature of this new approach is an excellent basis for continuing integrating probabilistic 487 information in rockfall hazard management. As reliable spatially distributed probabilistic information on rockfall trajectories is provided, such as the passing heights and kinetic energy distributions as well as the 
passing frequencies for each position on a slope, the proposed approach offers a complete data set for positioning and designing rockfall protective structures as well as for hazard zoning.

\section{References}

Agliardi, F., Crosta, G.B., 2003. High resolution three-dimensional numerical modelling of rockfalls. International Journal of Rock Mechanics and Mining Sciences. 40, 455-471.

Azzoni, A., Rossi P.P., Drigo E., Giani G.P., Zaninetti A., 1992. In situ observations of rockfalls analysis parameters Proceedings of the sixth International Symposium of Landslides. Balkema, Rotterdam, The Netherlands, pp. 307-314.

Azzoni, A., Barbera, G.L., Zaninetti A., 1995. Analysis and prediction of rockfalls using a mathematical model. International Journal of Rock Mechanics and Mining Sciences. 32, 709-724.

Azzoni, A., De Freitas, M.H., 1995. Experimentally gained parameters, decisive for rock fall analysis. Rock Mechanics and Rock Engineering. 28 (2), 111-124.

Berger, F., Dorren, L.K.A., 2006. Objective comparison of rockfall models using real size experimental data. Disaster mitigation of debris flows, slope failures and landslides. Universal Academy Press Inc., Tokyo, Japan, pp. 245-252.

Bourrier, F., Nicot, F., Darve, F., 2007. Rockfall modelling: Numerical simulation of the impact of a particle on a coarse granular medium. Proc. 10th Int. Congr. on NUmerical MOdel in Geomechanics. Balkema, Rotterdam, The Netherlands, pp. 699-705.

Bourrier, F. 2008. Modélisation de l'impact d'un bloc rocheux sur un terrain naturel, application à la trajectographie des chutes de bloc. PhD thesis, Institut Polytechnique de Grenoble, France.

Bourrier, F., Nicot, F., Darve, F., 2008a. Physical processes within a 2D granular layer during an impact. Granular Matter. 10 (6), 415-437. physical processes involved during the impact of a rock on a coarse soil. Proc. 2nd Euro Med. Symp. On Advances in Geomaterial and Structures. Publisher, location of publisher, pp. 501-506. 
515 Bozzolo, D., Pamini, R., 1986. Simulation of rock falls down a valley side. Acta Mechanica. 63, 113-130.

516 Chau, K. T., Wong, R.H.C., Lee, C. F., 1998. Rockfall Problems in Hong Kong and some new 517 Experimental Results for Coefficients of Restitution. International Journal of Rock Mechanics and $518 \quad$ Mining Sciences. 35(4-5), 662-663.

519 Chau, K.T., Wong, R.H.C., Wu, J.J., 2002. Coefficient of restitution and rotational motions of rockfall 520 impacts. International Journal of Rock Mechanics and Mining Sciences. 39, 69-77.

521 Chau, K.T., Tang, Y.F., Wong, R.H.C., 2004. GIS based rockfall hazard map for Hong Kong.

522 International Journal of Rock Mechanics and Mining Sciences. 41(1), 846-851.

523 Cruden, D.M., Varnes, D.J., 1996. Landslides types and processes : Chapter 3. In: Turner, A.K., Schuster, 524 R.L., (Eds.), Landslides: Investigation and Mitigation. Transportation research board, Special report 247, pp. 36-71.

526 Descoeudres, F., 1997. Aspects géomécaniques des instabilités de falaises rocheuses et des chutes de blocs. Publications de la société suisse de Mécanique des Sols et des Roches. 135, 3-11.

Dorren, L.K.A., 2003. A review of rockfall mechanics and modelling approaches. Progress in Physical Geography. 27 (1), 69-87.

Dorren, L.K.A., Berger, F., Le Hir, C., Mermin, E., Tardif, P., 2005. Mechanisms, effects and management implications of rockfall in forests. Forest Ecology and Management. 215(1-3), 183-195.

Dorren, L.K.A., Berger, F., Putters, U.S., 2006. Real size experiments and 3D simulation of rockfall on forested and non-forested slopes. Natural Hazards and Earth System Sciences. 6, 145-153.

Dudt, J.P., Heidenreich, B., 2001. Treatment of the uncertainty in a three-dimensional numerical simulation model of rockfalls. International Conference on Landslides. pp. 507-514. Geotechnical Journal. 30, 620-636.

538 Frattini, P., Crosta, G.B., Carrara, A., Agliardi, F., 2008. Assessment of rockfall susceptibility by integrating statistical and physically-based approaches. Geomorphology. 94 (3-4), 419-437. 
540 Guzzetti, F., Crosta, G., Detti, R., Agliardi F., 2002. STONE: a computer program for the three

541 dimensional simulation of rock-falls. Computer \& Geosciences. 28, 1079-1093.

542 Heidenreich, B., 2004. Small- and half-scale experimental studies of rockfall impacts on sandy slopes.

$543 \quad$ PhD Thesis, Ecole Polytechnique Fédérale de Lausanne, Swiss.

544 Interreg IIc., 2001. Prévention des mouvements de versants et des instabilités de falaise - Confrontation

545 des méthodes d'étude des éboulements rocheux dans l'arc alpin. Final report, Interreg IIc Program

$546 \quad$ Méditerranée occidentale et Alpes Latines.

547 Jaboyedoff, M., Dudt, J.P., Labiouse, V., 2005. An attempt to refine rockfall zoning based on kinetic

548 energy, frequency and fragmentation degree. Natural Hazards and Earth System Sciences. 5, 621-632.

549 Kobayashi, Y., Harp, E.L., Kagawa, T., 1990. Simulation of rockfalls triggered by earthquakes. Rock

$550 \quad$ Mechanics and Rock Engineering. 23, 1-20.

551 Nicot, F., Cambou, B., Mazzoleni, G., 2001. From a constitutive modelling of metallic rings to the design

552 of rockfall restraining nets. International Journal for Numerical and Analytical Methods in

553 Geomechanics. 25, 49-70.

554 Nicot, F., Gotteland, P., Bertrand, D., Lambert, S., 2007. Multiscale approach to geo-composite cellular 555 structures subjected to rock impacts. International Journal for Numerical and Analytical Methods in $556 \quad$ Geomechanics. 31, 1477-1515.

557 Paronuzzi, P., 1989. Probabilistic approach for design optimization of rockfall protective barriers.

558 Quarterly Journal of Engineering Geology and Hydrogeology. 22, 175-183.

559 Peila, D., Pelizza, S., Sasssudelli, F., 1998. Evaluation of behaviour of rockfall restraining nets by full $560 \quad$ scale tests. Rock Mechanics Rock Engineering. 31 (1), 1-24.

561 Pfeiffer, T.J., Bowen, T.D., 1989. Computer simulations of rockfalls. Bulletin of the Association of 562 Engineering Geology. 26, 135-146.

563 Raetzo, H., Lateltin, O., Bollinger, D., Tripet, J., 2002. Hazard assessment in Switzerland - Codes of 564 practice for mass movements. Bulletin of engineering Geology and the Environement. 61(3), 263-268. 
Scioldo, G., 2006. User guide ISOMAP \& ROTOMAP - 3D surface modelling and rockfall analysis. Geo\&Soft International.

Selby, M. J., 1993. Hillslope materials and processes. Oxford University Press, Oxford.

Ushiro, T., Shinohara, S., Tanida, K., Yagi, N., 2000. A study on the motion of rockfalls on Slopes.

Varnes, D.J., 1978. Slope movement types and processes. In: Schuster, R.L., Krizek, R.J., (Eds.),

Weber, D., and Englund, E., 1992. Evaluation and comparison of spatial interpolators. Mathematical Geology. 24, 381-391.

Whalley, W.B., 1984. Rockfalls. In: D. Brunsden, D., Prior, D.B. (Eds), Slope instability. John Wiley and Sons, New York, pp. 217-256.

Wu, S.S., 1985. Rockfall evaluation by computer simulation. Transportation Research Record. 1031, 1-5.

\section{$578 \quad$ List of figures}

579 Fig. 1. A) Google Earth image of the area around Grenoble (France) and the location of the study area; B)

580 location of the study area in the valley of the Eau d'Olle (Google Earth); C) picture of the study area from 581 a facing slope; D) map of the study area with an indication of 14 homogenous zones with different types 582 of surface roughness (dense fine dots = fine material; large dots = rough talus material, see Section 3.4), 583 the position of the two evaluation lines (EL1 and EL2), the release point and the 5 cameras.

584 Fig. 2. Experimental boulder volume distribution.

585 Fig. 3. Sequence of movie images.

586 Fig. 4. Example of A) the simulated rockfall trajectory plotted on a contour line map ( $x-y$ plan view); B) 587 the trajectory in the $x-z$ plane ( $z$-axis corresponds to the vertical direction); and C) the simulated velocity versus the $x$ coordinate. 
Fig. 5. Definitions of outgoing $\left(V_{\mathrm{t}}^{\text {out }}, V_{\mathrm{n}}^{\text {out }}\right.$, and $\left.\omega^{\text {out }}\right)$ and incident $\left(V_{\mathrm{t}}^{\text {in }}, V_{\mathrm{n}}^{\text {in }}\right.$, and $\left.\omega^{\text {in }}\right)$ velocity components used in the stochastic impact model and of the deviation angle $\delta$ characterising changes in boulder fall direction due to the rebound.

Fig. 6. Predictions of the mean values of the $R_{\mathrm{t}}$ and $R_{\mathrm{n}}$ coefficients versus the incident angle $\alpha^{\text {in }}$ using the 593 stochastic impact model.

594 Fig. 7. Plan view ( $x-y$ plane) illustrating the principle used for calculating the fall direction after rebound.

595 The deviation of the boulder from its direction before rebound is only allowed towards the aspect.

596 Fig. 8. Distribution of the velocities, passing heights, and translational kinetic energy for observed and 597 simulated trajectories for EL1 scaled to the observed values for both methods A ("size classes") and B 598 (“mean size”).

599 Fig. 9. Percentage of passing boulder versus distance from the release point for the experiments, method 600 A ("size classes") and method B ("mean size").

601 Fig. 10. Map of the simulated pass frequencies for methods A ("size classes") and B ("mean size") and 602 the observed stopping points (white dots).

603 Fig. 11. Distribution of the simulated rotational kinetic energy compared with the total kinetic energy for 604 EL1 and EL2 using method B ("mean size").

605 Fig. 12. Distribution of the simulated tangential incident energy $E_{t}^{\text {in }}$ compared with the total incident 606 energy $E_{t o t}^{\text {in }}$ for all the simulated rebounds using method B ("mean size").

607 Fig. 13. Distributions of the incidence angle $\alpha^{\text {in }}$ over all the simulations using method B ("mean size").

608

609 Fig. 14. Distribution of the tangential and normal restitution coefficients $R_{\mathrm{t}}$ and $R_{\mathrm{n}}$ over all simulations 610 using method B (“mean size”).

611 Fig. 15. Hillshade of the DEM showing the study site downslope from camera 5. The white dotted circle outlines the imperfect digital representation of the terrain. Black arrow 1 shows the main simulated 
613 trajectory. Black arrow 2 indicates the second main trajectory and its deviation due the artefact in the

614 DEM. The small grey circles represent the stopping positions of the experimental boulders.

615 Fig. 16. A typical field situation in Zone 3, where the surface material should be characterised by size 616 classes method.

617

\section{$618 \quad$ List of tables}

619 Table 1. For method A, the surface material size is defined using three roughness classes $R g_{70}, R g_{20}, R g_{10}$ 620 and, for method $\mathrm{B}$, the surface material size is defined using the parameter $R_{\mathrm{m}}$.

621 Table 2. Results after 10,000 simulation runs for both methods A ("size classes") and B ("mean size").

622 Table 3. Relative errors (RE) compared to observations after 10,000 simulation runs for both methods A 623 ("size classes") and B ("mean size").

624 Table 4. Kolmogorov-Smirnov tests (KS tests) compared to experimental distributions after 10,000

625 simulation runs for both methods A ("size classes") and B ("mean size"). 
626 Fig. 1.
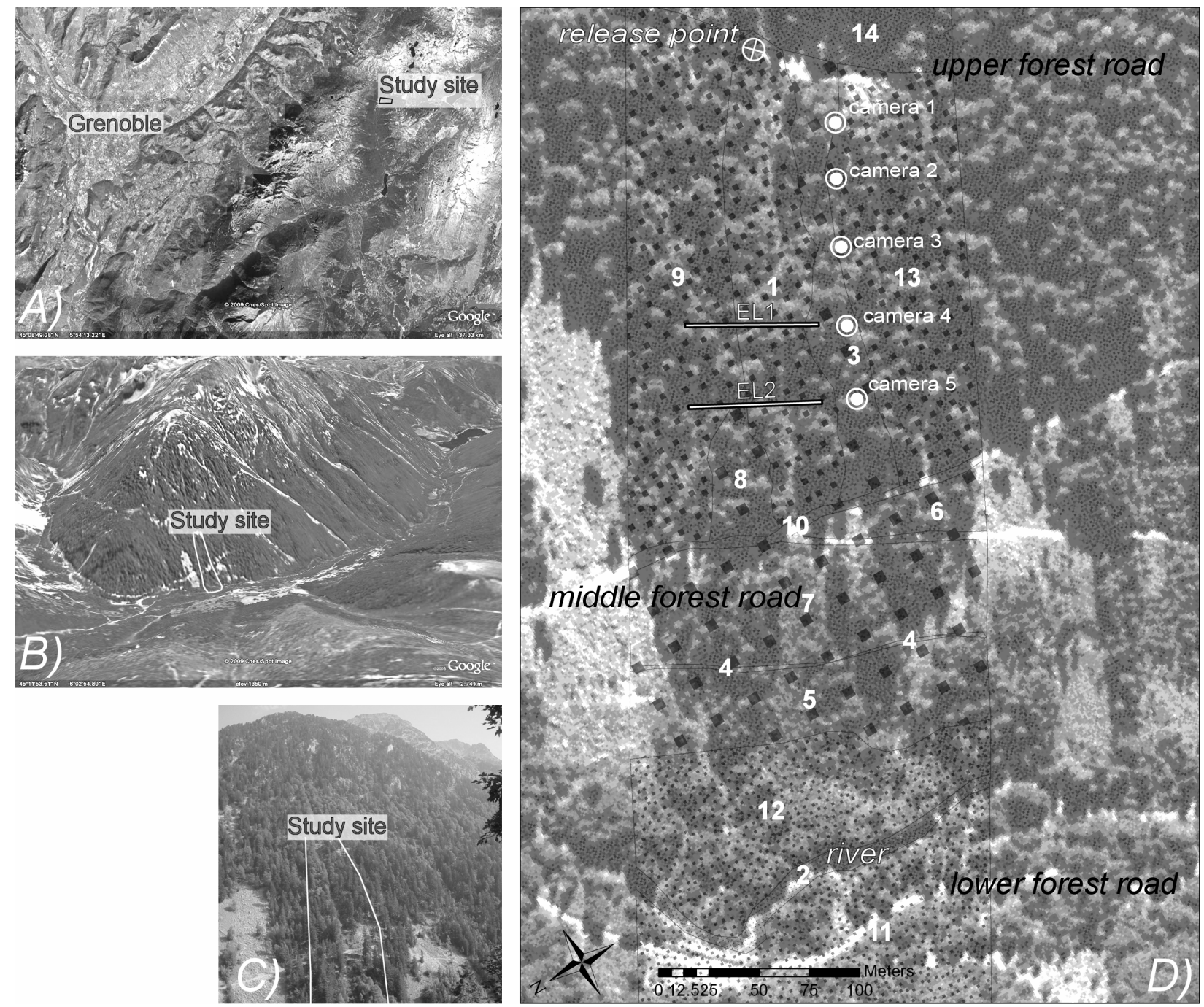
628 Fig. 2.

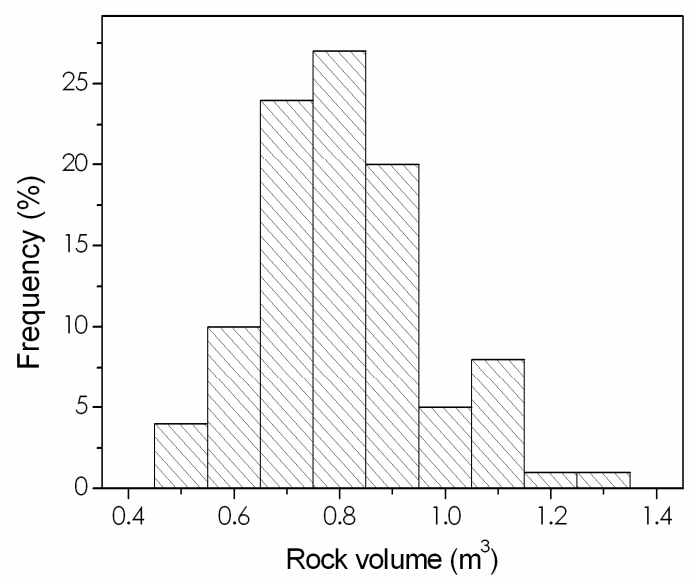

629 
630 Fig. 3.

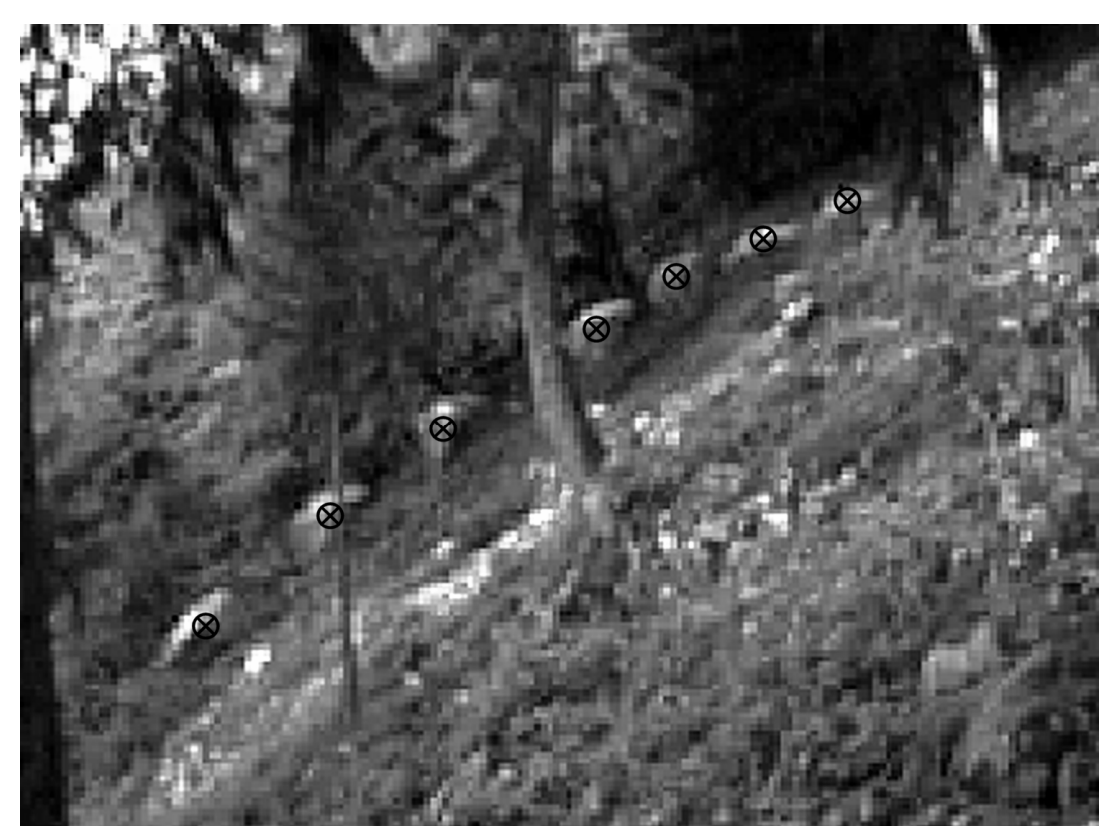

631 
632 Fig. 4.
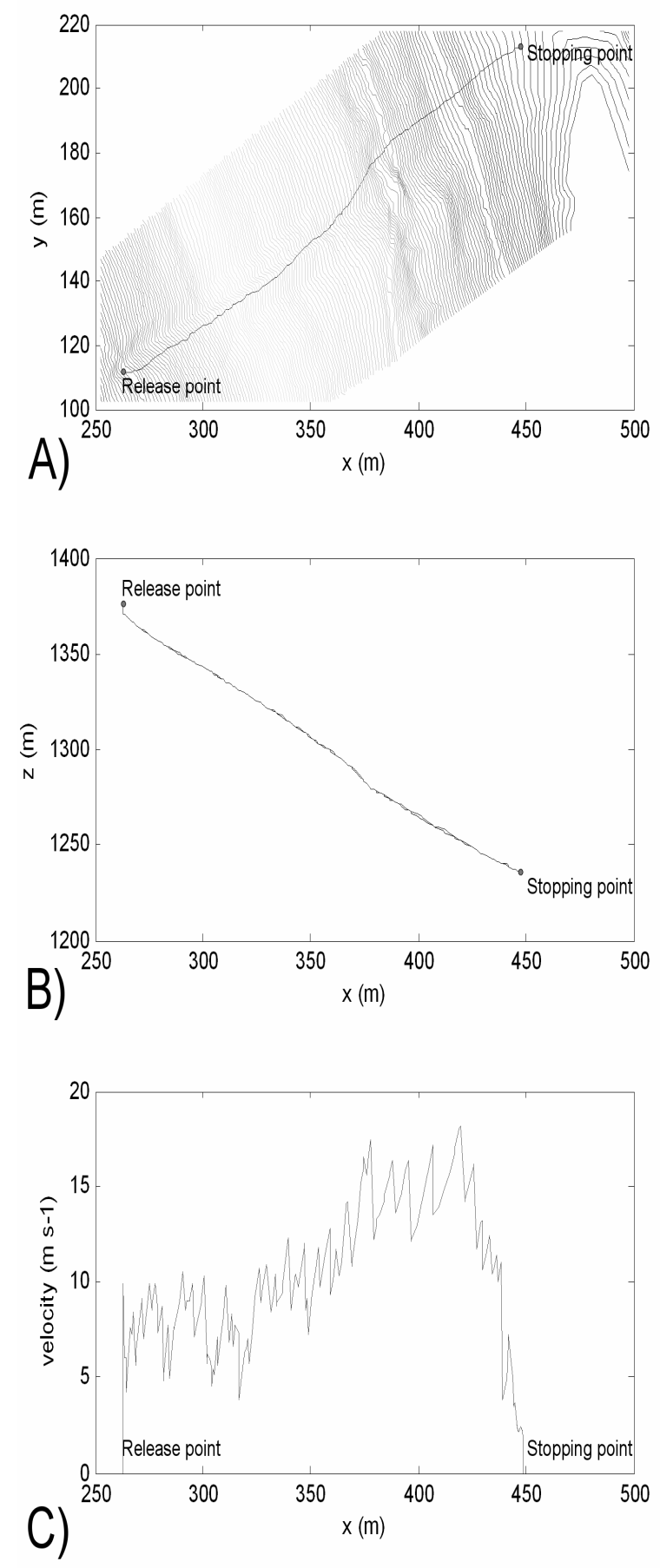
634 Fig. 5.

\section{Before rebound}

Perspective view

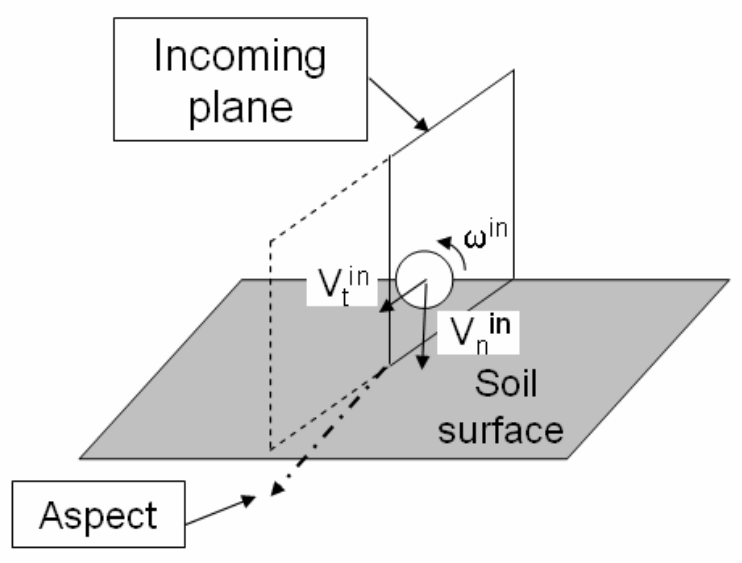

Projection in the incoming plane

635

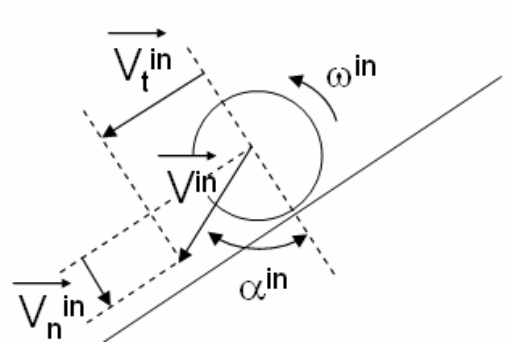

\section{After rebound}

\section{Perspective view}

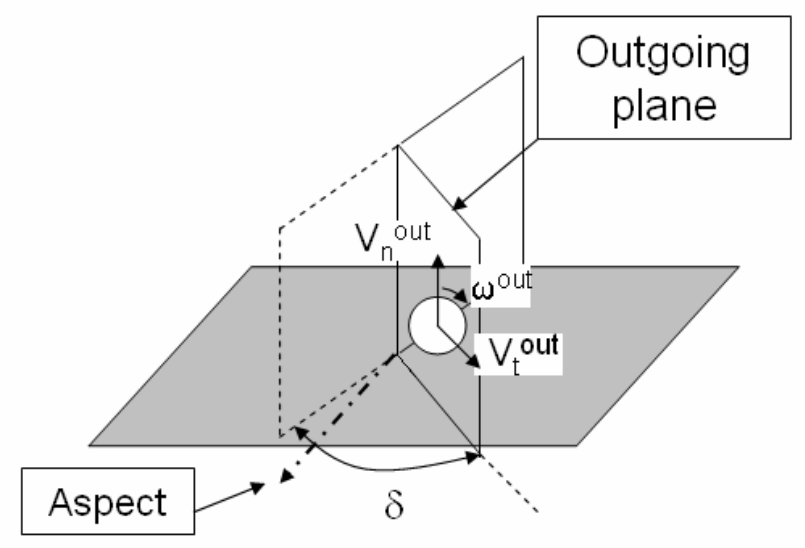

Projection in the outgoing plane

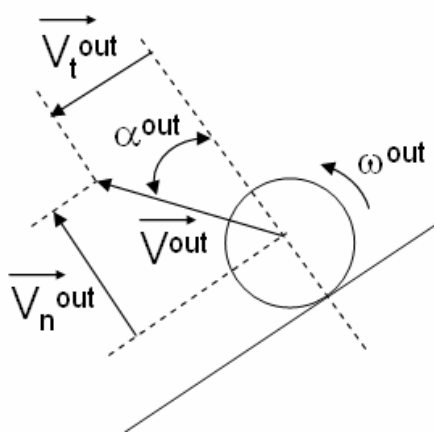


636 Fig. 6.
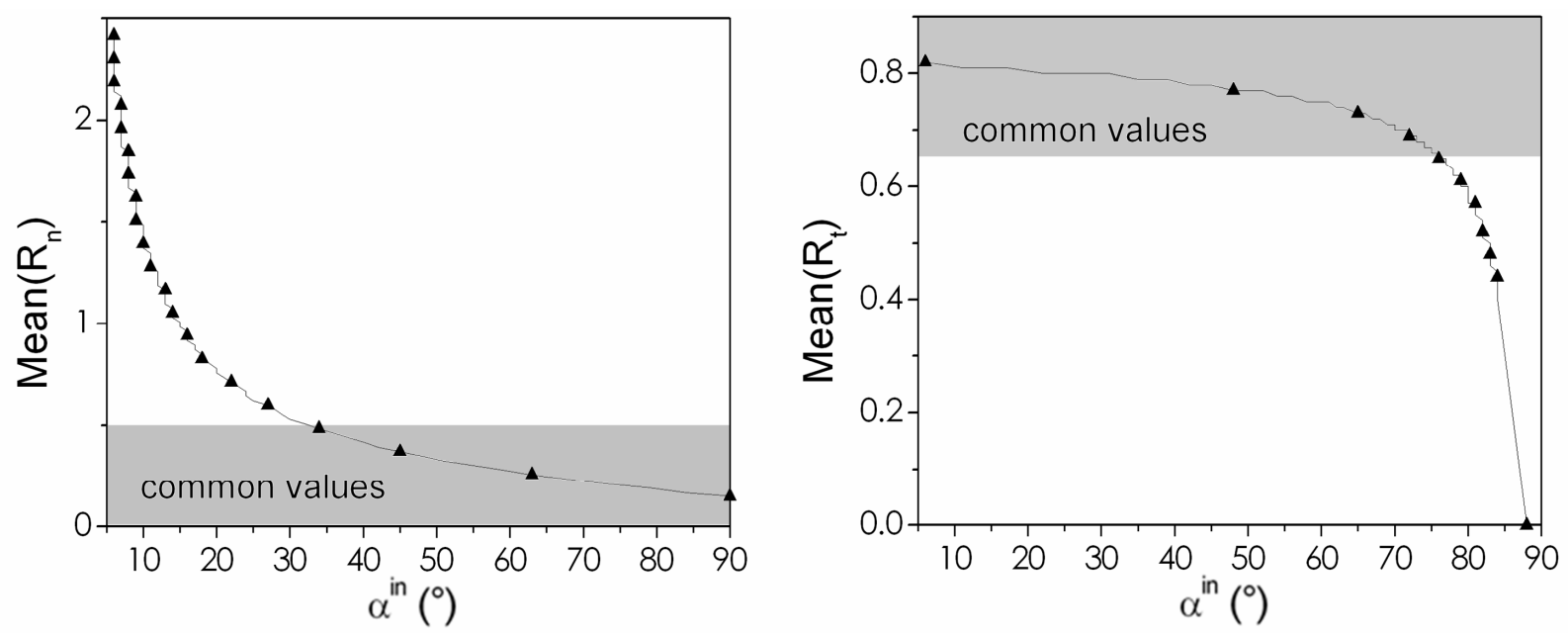

637 
638 Fig. 7.

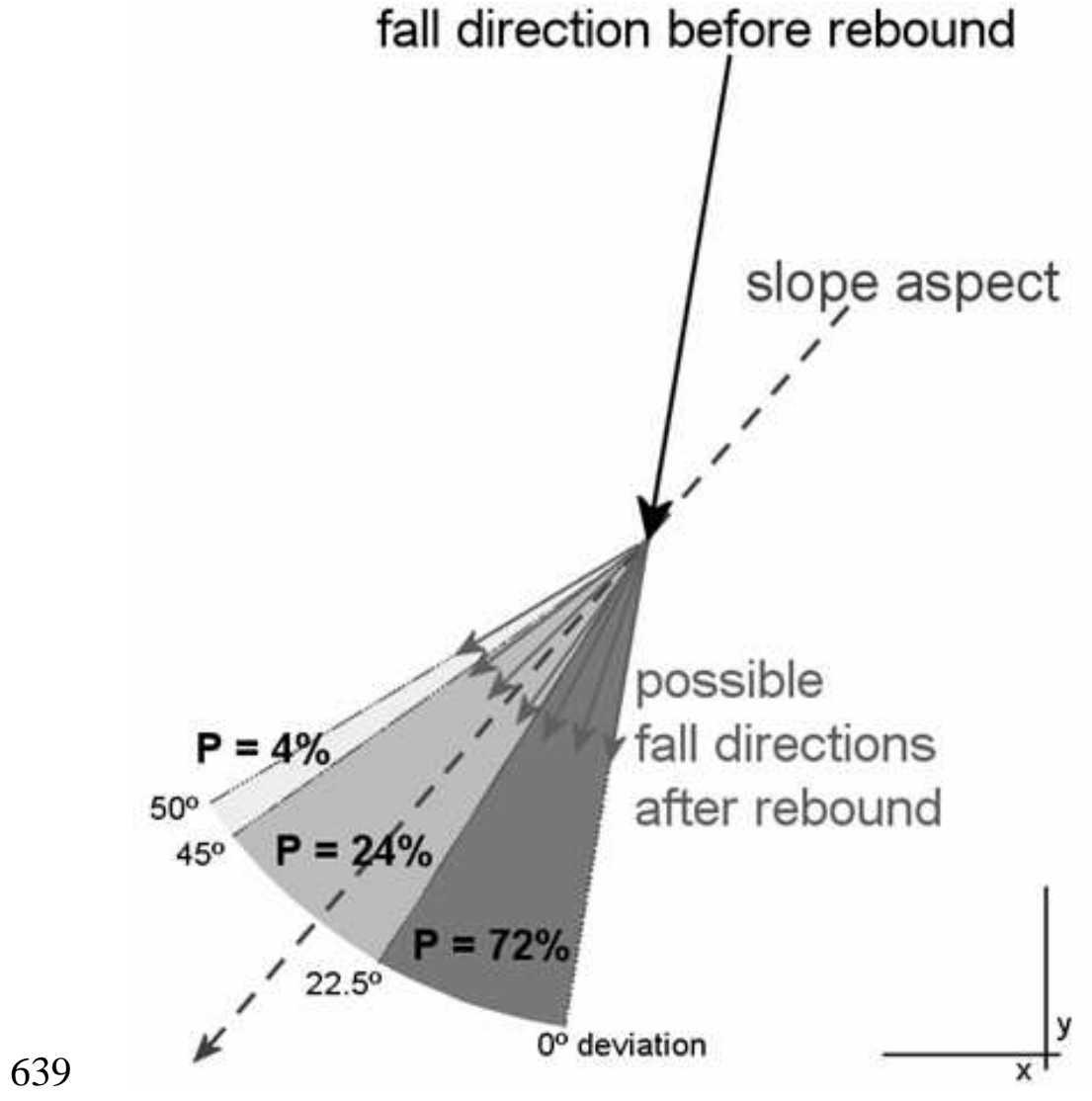


Fig. 8 .

\section{Experiments}
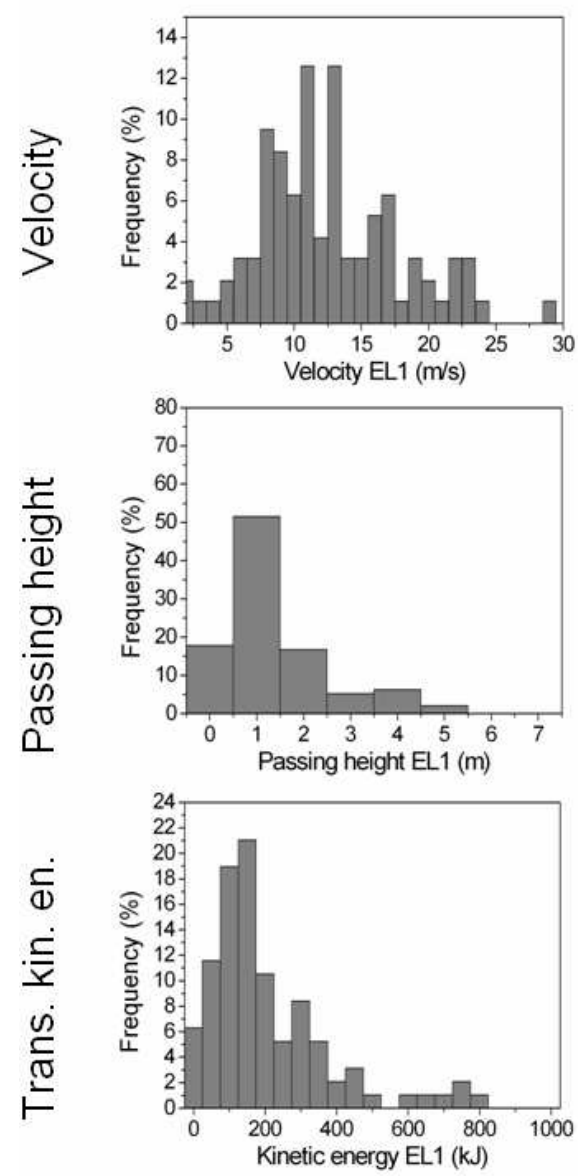

Method A
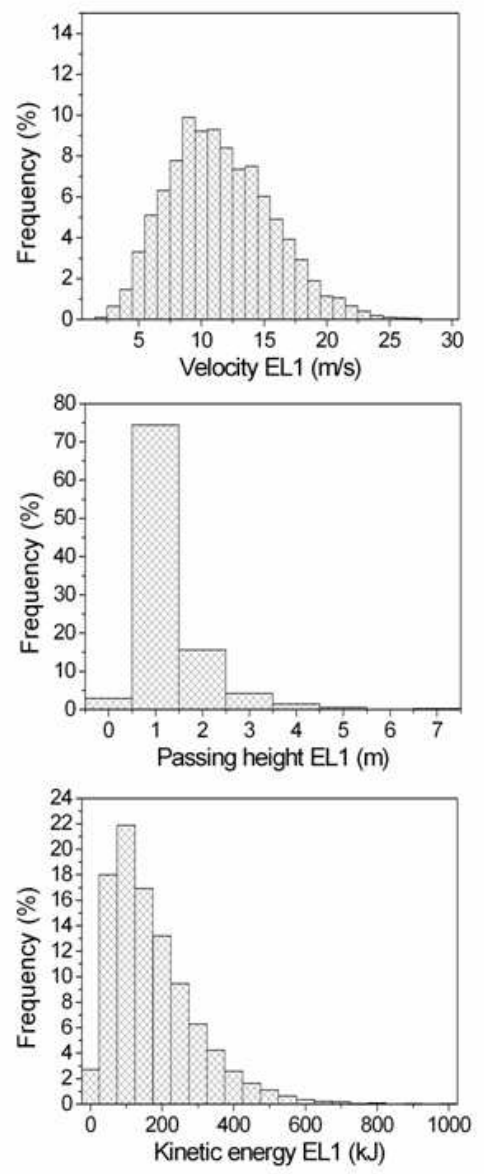

Method B
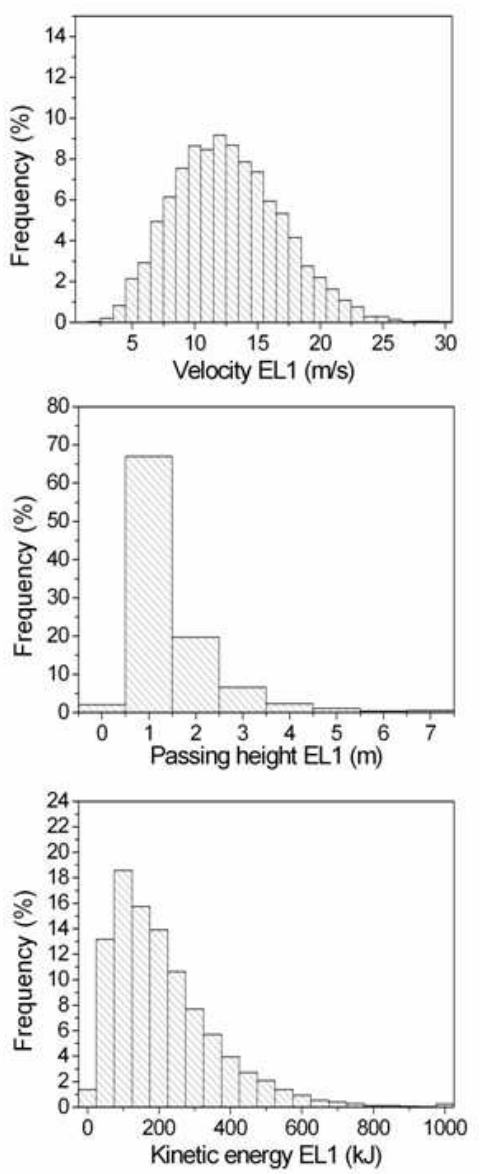
642 Fig. 9.

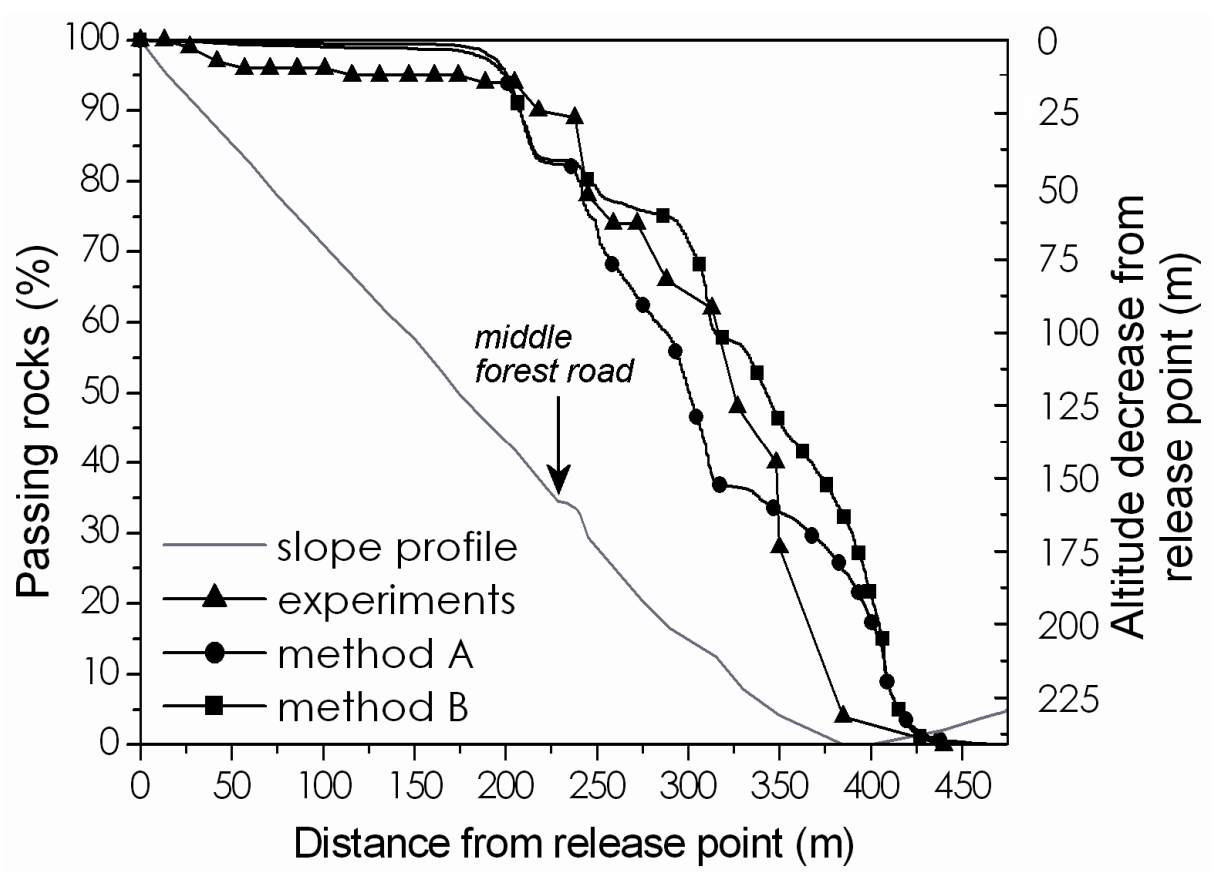


644 Fig. 10.

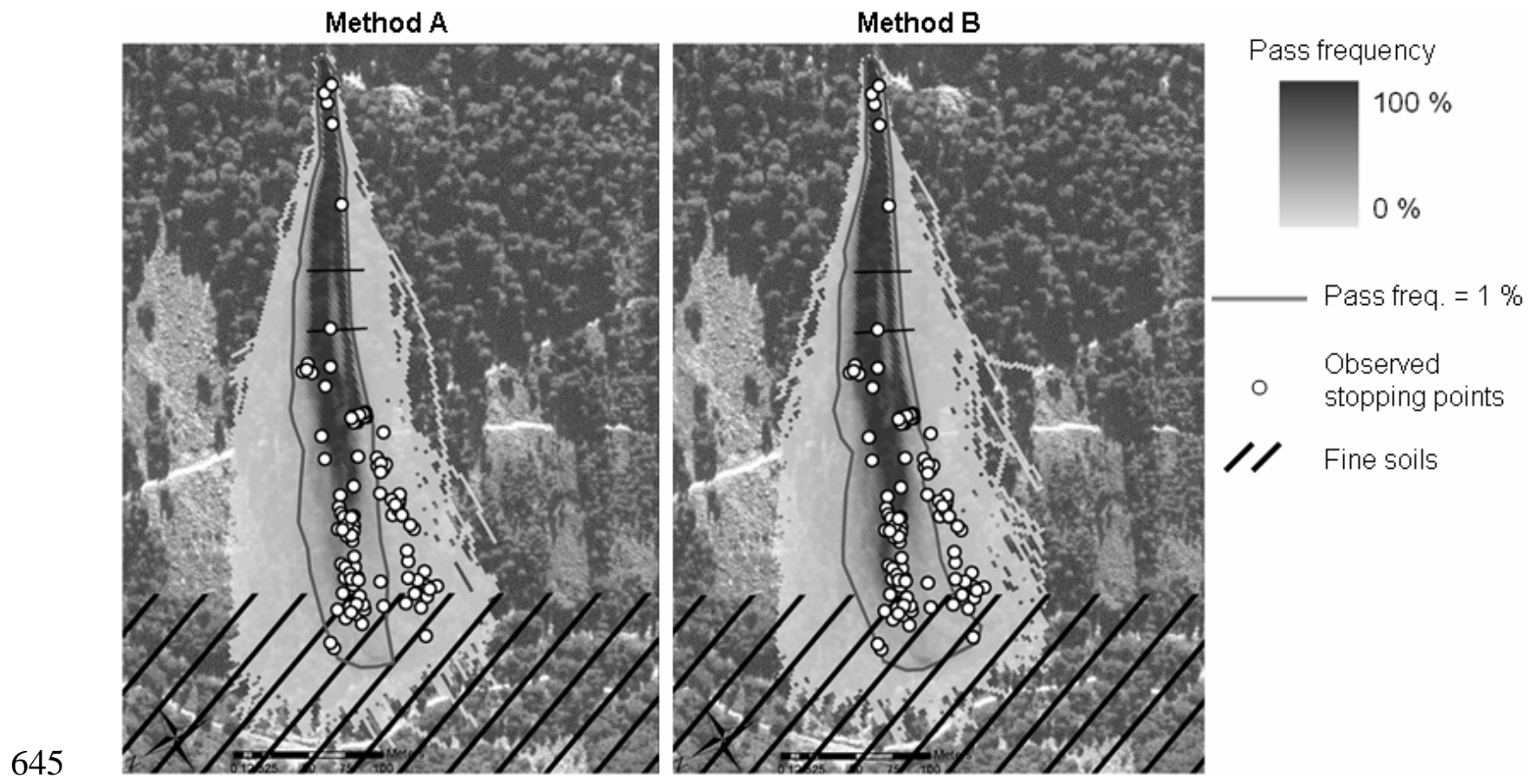


646 Fig. 11.

EL1

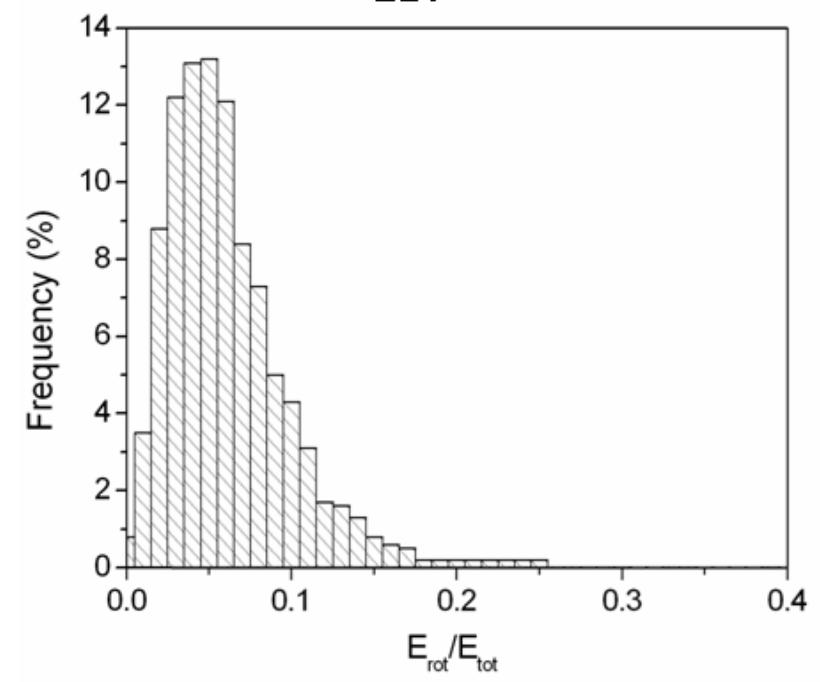

EL2

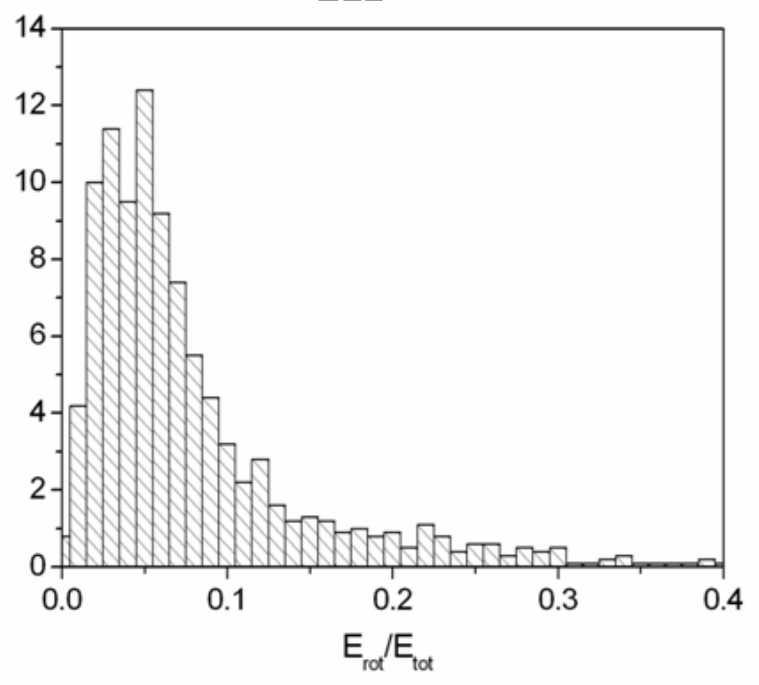


648 Fig. 12.

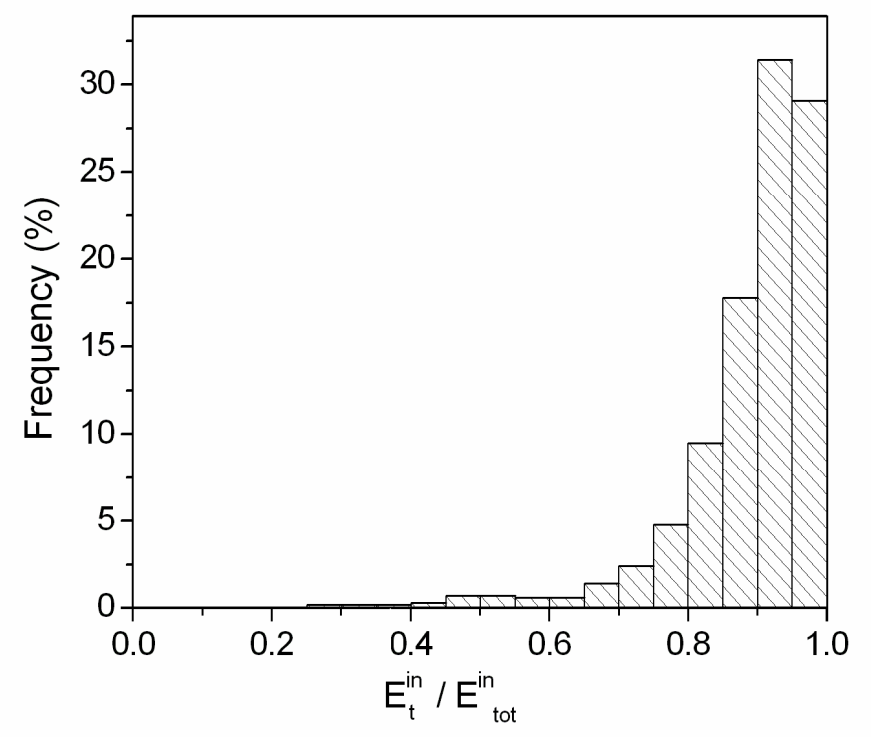

649 
650 Fig. 13.

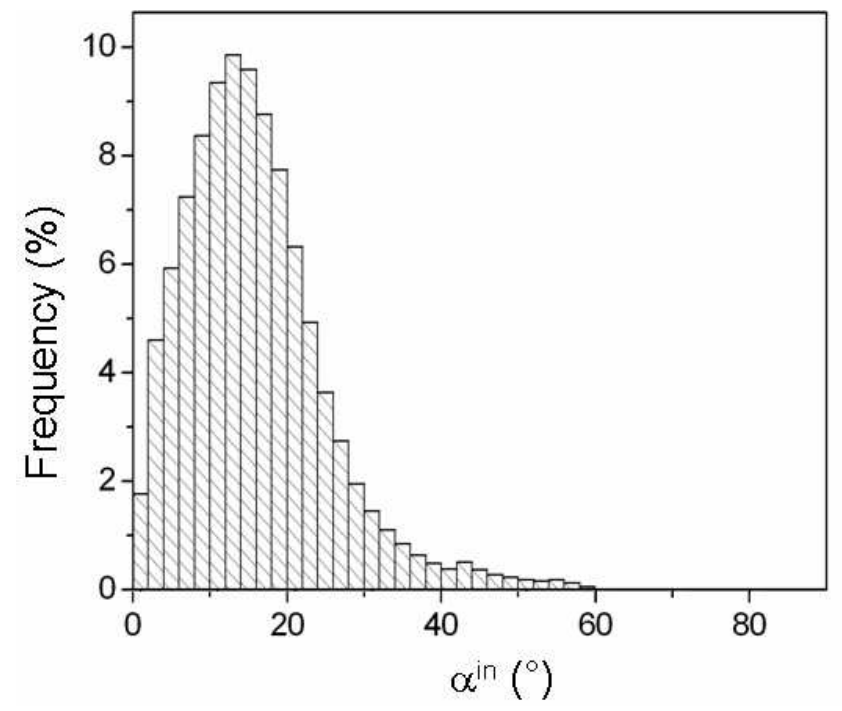

651 
652 Fig. 14.
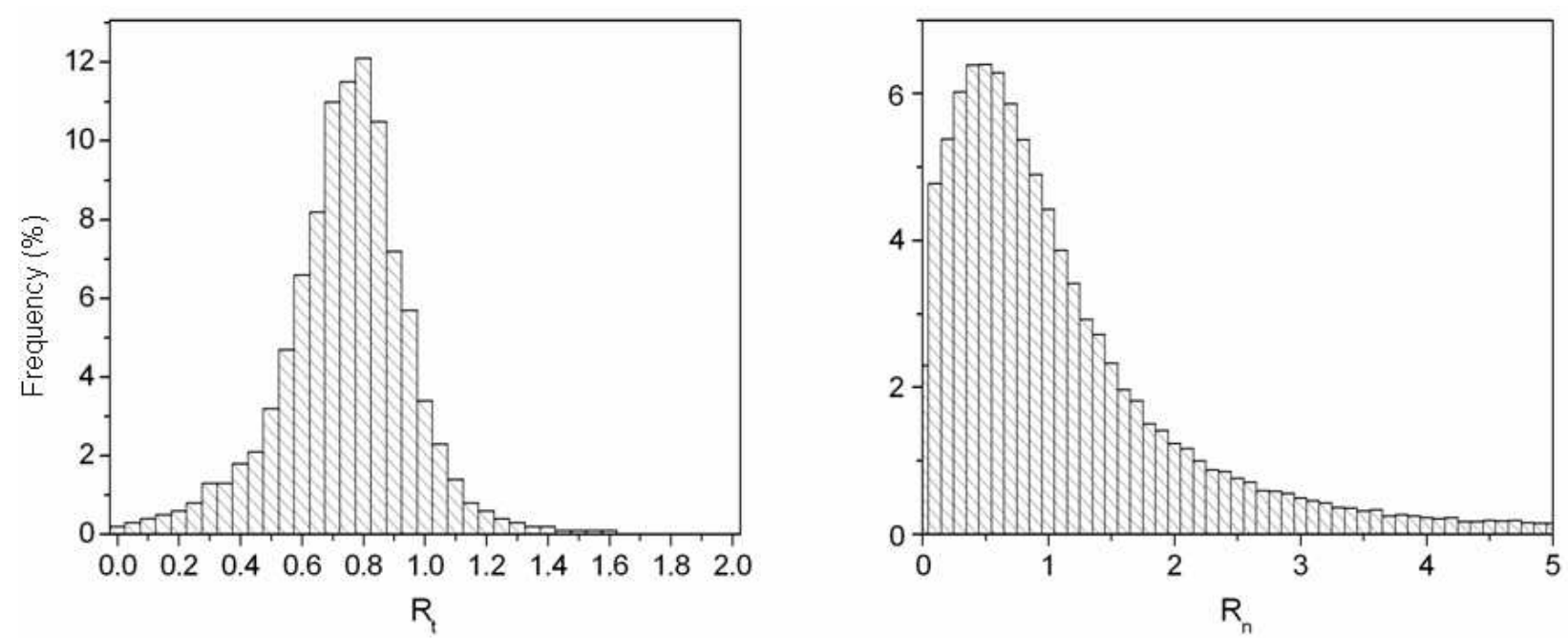

653 
654 Fig. 15.

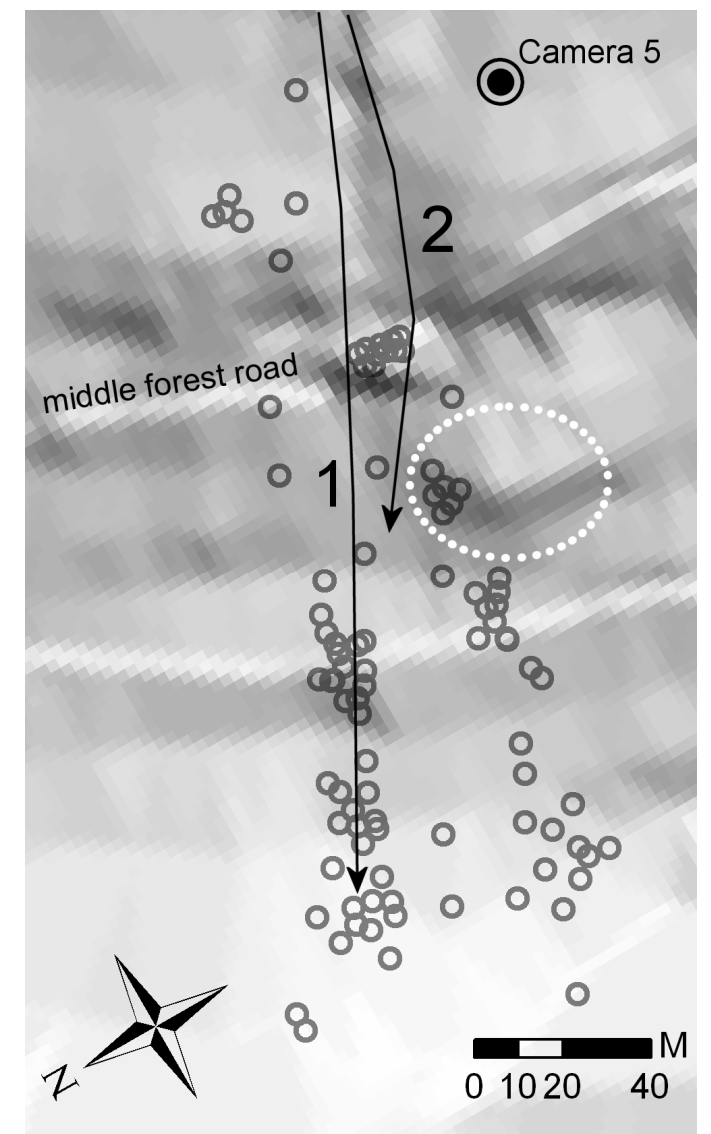

655 
656 Fig. 16.

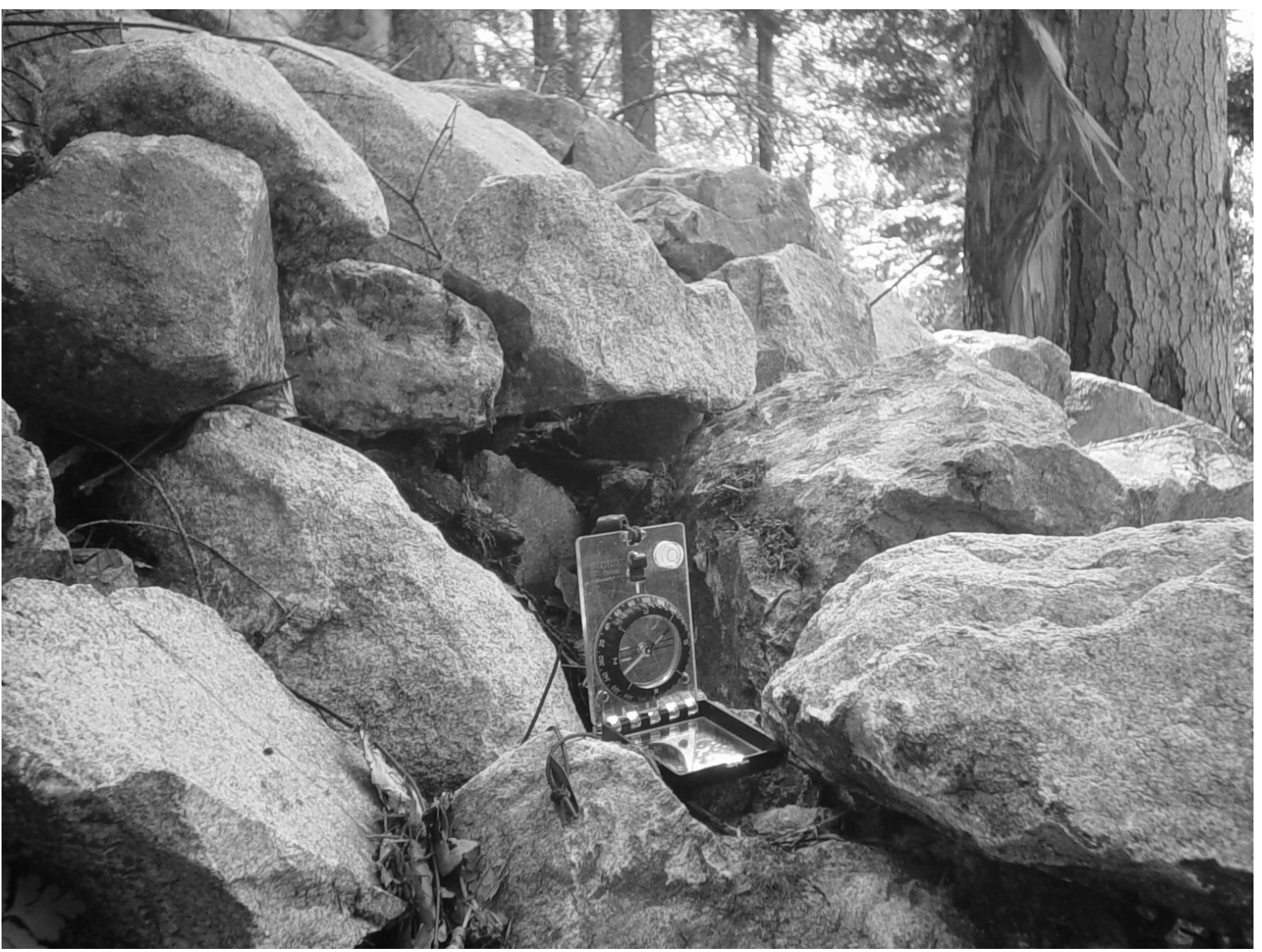

657 


\begin{tabular}{l|l|l|l|l|l}
\hline Zone & $R g_{70}(\mathrm{~m})$ & $R g_{20}(\mathrm{~m})$ & $R g_{10}(\mathrm{~m})$ & $R_{\mathrm{m}}(\mathrm{m})$ & Description \\
\hline 1 & 0.20 & 0.15 & 0.07 & 0.10 & Inside the avalanche channel \\
2 & Inf & Inf & Inf & Inf & River \\
3 & 0.30 & 0.10 & 0.45 & 0.18 & Zone covered with talus alongside the channel \\
4 & 0.50 & 0.30 & 0.10 & 0.25 & Old road on talus slope, covered with single blocks \\
5 & 0.40 & 0.20 & 0.10 & 0.25 & Talus slope downslope of middle forest road \\
6 & 0.50 & 0.25 & 0.75 & 0.25 & Rough talus slope downslope of middle forest road \\
7 & 0.50 & 0.28 & 0.90 & 0.25 & Roughest part of the talus slope downslope of \\
8 & 0.40 & 0.25 & 0.50 & 0.25 & Small block accumulation \\
9 & 0.20 & 0.05 & 0.10 & 0.10 & North-east forested part of talus slope \\
10 & 0.50 & 0.30 & 0.10 & 0.10 & Irregular forest road on talus slope \\
11 & 0.05 & 0.05 & 0.05 & 0.05 & Soils in valley bottom \\
12 & 0.02 & 0.05 & 0.10 & 0.03 & Fine soils in valley bottom \\
13 & 0.25 & 0.15 & 0.10 & 0.10 & South-west forested part of talus slope \\
14 & 0.10 & 0.20 & 0.30 & 0.10 & Upper forest road \\
\hline
\end{tabular}




\begin{tabular}{|c|c|c|c|c|c|c|c|c|c|}
\hline & \multicolumn{3}{|c|}{ Velocity $\left(\mathrm{m} . \mathrm{s}^{-1}\right)$} & \multicolumn{3}{|c|}{ Passing height (m) } & \multicolumn{3}{|c|}{ Trans. kin. en. (kJ) } \\
\hline & Mean & \begin{tabular}{|l|} 
Std. \\
Dev.
\end{tabular} & Max. & Mean & \begin{tabular}{|l|} 
Std. \\
Dev.
\end{tabular} & Max. & Mean & \begin{tabular}{|l|} 
Std. \\
Dev.
\end{tabular} & Max. \\
\hline EL1 ${ }^{a}$ observed & 12.5 & 5.2 & 28.1 & 1.4 & 1.1 & 5.0 & 205 & 169 & 786 \\
\hline EL1 method A & 11.5 & 4.2 & 27.7 & 1.2 & 0.9 & 10.4 & 175 & 126 & 1081 \\
\hline EL1 method B & 12.7 & 4.3 & 30.3 & 1.4 & 1.0 & 11.0 & 213 & 152 & 1332 \\
\hline EL2 observed & 13.8 & 5.5 & 28.9 & 1.6 & 1.4 & 6.2 & 245 & 196 & 958 \\
\hline EL2 method A & 10.9 & 4.7 & 29.6 & 1.2 & 1.0 & 15.5 & 167 & 139 & 1174 \\
\hline EL2 method B & 12.1 & 5.1 & 31.8 & 1.4 & 1.1 & 12.7 & 207 & 173 & 1575 \\
\hline
\end{tabular}

660

${ }^{\mathrm{a}} \mathrm{EL}=$ Evaluation line.

661 


\begin{tabular}{l|l|l|r|r|r|l|l|r|r}
\hline & \multicolumn{3}{|l|}{ RE velocity (\%) } & \multicolumn{3}{l|}{ RE passing height (\%) } & \multicolumn{2}{l}{ RE Trans. kin. en. (\%) } \\
\cline { 2 - 9 } & \multicolumn{1}{l}{ Mean } & $\begin{array}{l}\text { Std. } \\
\text { Dev. }\end{array}$ & Max. & Mean & $\begin{array}{l}\text { Std. } \\
\text { Dev. }\end{array}$ & Max. & Mean & $\begin{array}{l}\text { Std. } \\
\text { Dev. }\end{array}$ & Max. \\
\hline EL1 method A & -8 & -19 & -1 & -14 & -18 & 108 & -15 & -25 & 38 \\
EL1 method B & 2 & -17 & 8 & 0 & -9 & 120 & 4 & -10 & 69 \\
\hline EL2 method A & -21 & -15 & 2 & -25 & -29 & 150 & -32 & -29 & 23 \\
EL2 method B & -12 & -7 & 10 & -13 & -21 & 105 & -16 & -12 & 64 \\
\hline
\end{tabular}


663 Table 4.

\begin{tabular}{l|l|r|l|r|r|r|}
\hline & \multicolumn{3}{|l|}{ Velocity } & \multicolumn{2}{l|}{ Passing height } & \multicolumn{2}{l|}{ Trans. kin. en. } \\
\cline { 2 - 8 } & $\begin{array}{l}\text { KS test } \\
\text { 0: not rejected } \\
\text { 1: rejected }\end{array}$ & P-value & $\begin{array}{l}\text { KS test } \\
\text { 0: not rejected } \\
\text { 1: rejected }\end{array}$ & P-value & $\begin{array}{l}\text { KS test } \\
\text { 0: not rejected } \\
\text { 1: rejected }\end{array}$ & P-value \\
\hline EL1 method A & 0 & 0.2225 & 1 & 0.0385 & 0 & 0.1772 \\
EL1 method B & 0 & 0.2172 & 0 & 0.0570 & 0 & 0.1421 \\
\hline EL2 method A & 1 & 0.0033 & 1 & 0.0224 & 1 & 0.0223 \\
EL2 method B & 0 & 0.1022 & 1 & 0.0366 & 0 & 0.2911 \\
\hline
\end{tabular}

664 